\title{
Evaluation of Prenatal Exposure to Bisphenol Analogues on Development and Long-Term Health of the Mammary Gland in Female Mice
}

\author{
Deirdre K. Tucker, ${ }^{1,2}$ Schantel Hayes Bouknight, ${ }^{3}$ Sukhdev S. Brar, ${ }^{4}$ Grace E. Kissling, ${ }^{5}$ and Suzanne E. Fenton ${ }^{2}$ \\ ${ }^{1}$ Curriculum in Toxicology, University of North Carolina at Chapel Hill, Chapel Hill, North Carolina, USA \\ ${ }^{2}$ Division of the National Toxicology Program (DNTP), NTP Laboratory, National Institute of Environmental Health Sciences (NIEHS), National Institute of \\ Health (NIH), Research Triangle Park, North Carolina, USA \\ ${ }^{3}$ Charles River Laboratories, Inc., Durham, North Carolina, USA \\ ${ }^{4}$ DNTP, Cellular and Molecular Pathology Branch, NIEHS, Research Triangle Park, North Carolina, USA \\ ${ }^{5}$ Division of Intramural Research, Biostatistics and Computational Biology Branch, NIEHS, Research Triangle Park, North Carolina, USA
}

\begin{abstract}
BACKGROUND: Continued efforts to phase out bisphenol A (BPA) from consumer products have been met with the challenges of finding safer alternatives.
OвJECTIVES: This study aimed to determine whether early-life exposure to BPA and its related analogues, bisphenol AF (BPAF) and bisphenol S (BPS), could affect female pubertal mammary gland development and long-term mammary health in mice.
\end{abstract}

Methods: Timed pregnant CD-1 mice were exposed to vehicle, BPA $(0.5,5,50 \mathrm{mg} / \mathrm{kg}), \mathrm{BPAF}(0.05,0.5,5 \mathrm{mg} / \mathrm{kg}), \mathrm{or} \mathrm{BPS}(0.05,0.5,5 \mathrm{mg} / \mathrm{kg})$ via oral gavage between gestation days 10-17. Mammary glands were collected from resulting female offspring at postnatal day (PND) 20, 28, 35, and 56, and at 3, 8, and 14 months for whole mount, histopathological evaluation, and quantitative real-time polymerase chain reaction (qPCR); serum steroid concentrations were also measured at these time points.

RESULTS: In the bisphenol-exposed mice, accelerated mammary gland development was evident during early puberty and persisted into adulthood. By late adulthood, mammary glands from bisphenol-exposed female offspring exhibited adverse morphology in comparison with controls; most prominent were undifferentiated duct ends, significantly more lobuloalveolar hyperplasia and perivascular inflammation, and various tumors, including adenocarcinomas. Effects were especially prominent in the BPAF $5 \mathrm{mg} / \mathrm{kg}$ and BPS $0.5 \mathrm{mg} / \mathrm{kg}$ groups. Serum steroid concentrations and mammary mRNA levels of Esrl, Pgr, Ar, and Gperl were similar to controls.

ConcLusions: These data demonstrate that prenatal exposure of mice to BPAF or BPS induced precocious development of the mammary gland, and that siblings were significantly more susceptible to spontaneous preneoplastic epithelial lesions and inflammation, with an incidence greater than that observed in vehicle- and BPA-exposed animals. https://doi.org/10.1289/EHP3189

\section{Introduction}

The mammary gland is an essential tissue that is required for lactation and infant nourishment. Like other female reproductive tissues, many hormones and growth factors influence mammary tissue, with the primary drivers depending on the stage of development. Steroid hormones regulate ductal growth, elongation, branching, and differentiation, and exposure to environmental chemicals that mimic or interfere with the action of endogenous hormones can alter normal mammary development (Rudel et al. 2011). The earliest stages of mammary development, during fetal mammary bud formation in late gestation and the primary stages of ductal branching that occur just prior to and after birth, have been reported as susceptible time points for the effects of endocrine-disrupting chemicals (EDCs) (Enoch et al. 2007; Macon et al. 2011; Padilla-Banks et al. 2006; Tucker et al. 2015). Studies of prenatal and perinatal exposure to human relevant doses of bisphenol A (BPA) in rodents have reported increased epithelial tissue growth, decreased apoptosis, decreased latency, and increased incidence of preneoplastic and neoplastic lesions in the mammary gland (Acevedo et al. 2013; Durando et al. 2007; Markey et al. 2001; Muñoz-de-Toro et al. 2005). Several rodent studies have also linked BPA exposure at

Address correspondence to S. E. Fenton, PhD, 111 T.W. Alexander Dr., MD E1-08, ResearchTriangle Park, NC 27709, USA. Telephone: (984) 287-4182. Email: fentonse@niehs.nih.gov

Supplemental Material is available online (https://doi.org/10.1289/EHP3189).

The authors declare they have no actual or potential competing financial interests.

Received 4 December 2017; Revised 25 June 2018; Accepted 27 June 2018; Published 10 August 2018.

Note to readers with disabilities: $E H P$ strives to ensure that all journal content is accessible to all readers. However, some figures and Supplemental Material published in EHP articles may not conform to 508 standards due to the complexity of the information being presented. If you need assistance accessing journal content, please contact ehponline@niehs.nih.gov. Our staff will work with you to assess and meet your accessibility needs within 3 working days. human-relevant doses to neurobehavioral deficits (Dessi-Fulgheri et al. 2002; Palanza et al. 2008; Ryan and Vandenbergh 2006), reproductive alterations (Markey et al. 2005; Timms et al. 2005), and hepatic tumors (Weinhouse et al. 2014).

BPA is a chemical commonly used in the manufacturing of plasticizers, epoxy resins, thermal paper, dental sealants, and linings of canned foods. The fourth National Report on Human Exposure to Environmental Chemicals (CDC 2017) suggested that the highest human urinary geometric mean for total BPA in all age groups occurred in the United States between 2003 and 2004, a time when BPA was detected in urine samples of $>90 \%$ of the general population (Calafat et al. 2008; Ye et al. 2015). BPA has also been recovered in human maternal serum (Schönfelder et al. 2002), maternal urine (Gerona et al. 2016), amniotic fluid (Pinney et al. 2017), and fetal cord blood (Schönfelder et al. 2002; Todaka and Mori 2002), suggesting that BPA readily crosses the placenta to the unborn child. Distribution into milk in humans (Mendonca et al. 2014; Sun et al. 2004) and rodents (Doerge et al. 2010; Okabayashi and Watanabe 2010) has also been reported. Exposure to BPA during the fetal or perinatal period is of concern, based on many reports demonstrating BPA's estrogenic and endocrinedisrupting properties in both the toxicology and epidemiological literature (reviewed in Gore et al. 2015). There remains some controversy surrounding BPA's impact on human health; as human exposures are low when measured in urine, these chemicals are thought to be quickly cleared, and biological activity of BPA metabolites in humans is poorly understood (Vandenberg et al. 2013). However, numerous epidemiological studies report a range of health effects associated with BPA exposure, such as increased effects related to metabolic disease, neurobehavior, growth and development, and reproductive tissue anomalies or dysfunction (reviewed in Rochester et al. 2013 and Gore et al. 2015).

In 2010, the World Health Organization (WHO 2010) estimated that breastfed infants between the ages of 0-6 months were exposed to $0.3 \mu \mathrm{g} / \mathrm{kg}$ body weight (BW) BPA daily, and BPA levels in infants fed formula from polycarbonate bottles were 
estimated at eight times breast-fed concentrations, and those given canned formula in polycarbonate-free bottles were exposed to $0.5 \mu \mathrm{g} / \mathrm{kg} \mathrm{BW}$ (WHO 2010). This finding suggested that most of the exposure that infants acquired was through plastic bottles. Petitioning from baby bottle manufacturers prompted the FDA to ban the use of BPA in baby bottles and sippy cups in 2012 and phase out use in infant formula packaging in 2013 (U.S. FDA 2014). However, infants and children were also exposed through additional routes, including gestational and lactational transfer, inhalation and ingestion of contaminated dust, and oral exposures through food and beverage containers/films (Liao and Kannan 2013; Liao et al. 2012b; Mendonca et al. 2014). The combination of FDA's BPA use restrictions and voluntary recalls by some manufacturers have led to the integration of other bisphenol analogues that demonstrate similarity in structure and activity to BPA (Pelch et al. 2017) into paper- and food-containing products, dental sealants, or food-processing equipment.

The fluorinated bisphenol analogue, Bisphenol AF (BPAF), was nominated for health effects assessment by the National Toxicology Program (NTP) in 2008 because estrogenic activity assays reported that BPAF $(53.4 \mathrm{nM})$ is an agonist and binds to estrogen receptor alpha $(\mathrm{ER} \alpha)$ with $\sim 20 \mathrm{x}$ greater affinity than BPA $(1030 \mathrm{nM})$, and BPAF is a full antagonist for ER $\beta$ (Kitamura et al. 2005; Matsushima et al. 2010). Production of BPAF is $10,000-500,000$ pounds per year and considered to be moderate (NTP 2008); but BPAF has been detected in contaminated air, soil, water, and sediment downstream of factories involved in fluoroelastomer production (Song et al. 2012; Wang et al. 2015). Female workers in the molding and casting machine operations industry are exposed to BPAF (NIOSH 1990), and BPAF was detected in the urine of a Chinese population downstream from a manufacturing plant (Yang et al. 2014). The general population may be exposed to BPAF through products used for dental sealants and composites, as well as food containers and films (Hashimoto et al. 2001; Liao and Kannan 2013).

Bisphenol S (BPS), a common sulfated BPA analogue, has been measured in thermal receipt papers, currency bills, and canned foods, and it is also used as a modifier for leather fiber, for polymers, and as an epoxy curing agent (Liao and Kannan 2013; Liao et al. 2012c). Similar to BPA, BPS was detected in $100 \%$ of indoor dust samples from the United States, China, Japan, and Korea, indicating that oral ingestion, dermal exposure, and inhalation are all potential routes of exposure (Liao et al. 2012b). Human exposure to BPS has been confirmed by urinary measurements in the United States and seven Asian countries, with the highest concentrations found in Japan, followed by the United States (Liao et al. 2012a, 2012c). In a study of cashiers, an occupation that requires extensively handling receipt paper, urine BPS concentrations were significantly increased in post-shift measurements in comparison with pre-shift measurements (Thayer et al. 2016).

Recent data from the Center for Disease Control (with human samples collected in 2013-2014; see CDC 2017, Volume 1, pp. 42-43) has shown an overall decline in the creatinine-adjusted urinary BPA geometric mean concentration in both sexes, and all ethnicities and age groups, between 2003 and 2014 (CDC 2017). Similarly, urinary measurements from convenience sampling of the U.S. general population between 2000 and 2014 showed a decline in the percent detection and geometric mean urinary BPA concentration, but the percentage of samples with detectable BPS, and the average concentrations measured, steadily increased, suggesting a change in exposure trends for BPS and BPA (Ye et al. 2015). Although BPAF was below the limit of detection (<LOD) in most urine samples tested (detected in $<3 \%$; Ye et al. 2015), BPAF has been extracted from mammary and abdominal tissue, indicating that it may partition to adipose-rich tissues, including the mammary gland because of its fluorine moiety (Fernández et al.
2004). This finding may also suggest that urine is not the most accurate matrix for assessing BPAF exposure. To date, no study has evaluated BPAF effects on the developing mammary gland, nor any latent health repercussions that may be associated with early-life exposure. BPS, however, has recently been reported to alter the lactating mammary gland (LaPlante et al. 2017) and mammary gland development of pups following perinatal exposure in CD-1 mice (Kolla et al. 2018). The long-term mammary gland effects of prenatal exposure to BPS are uncharacterized.

The aim of this study was to determine whether fetal exposures to BPAF or BPS at relatively low concentrations can alter postnatal and adult mammary gland development of mice in a similar fashion to BPA. Pregnant mice were orally exposed to vehicle, BPA, BPS, and BPAF during the period of fetal mammary gland development, and their female offspring were evaluated until they were 14 months old for effects on puberty and mammary gland lesion development.

\section{Methods}

\section{Chemicals and Dosing Solutions}

All chemicals, except Bisphenol AF (3B Pharmachem International Co. Ltd.), were obtained from Sigma Aldrich. The purity of these test chemicals was measured by the NTP chemistry contract and was found to be $\geq 97.5 \%$ (BPS), $98 \%$ (BPAF), and $\geq 99.0 \%$ (BPA) pure. All chemicals arrived in powdered form and were placed in a DryKeeper (Sanplatec Corp.) at 25\% humidity. Dosing solutions were prepared daily by dissolving in pure sesame oil (Jedwards International, Inc.,) and stored in clear glass vials with screw-on caps to prevent exogenous bisphenol contamination.

\section{Animals}

Outbred timed pregnant CD-1 mice were purchased from Charles River Laboratories, with breeding having occurred in the evening. Females observed to have a copulatory plug the following morning were considered to be at gestation day (GD) 0.5 (GD 0). Animals were received on GD 8.5 and acclimated $2 \mathrm{~d}$ prior to dosing. Throughout the studies, animals were maintained at a controlled temperature of $20^{\circ}-24^{\circ} \mathrm{C}$ with $40-60 \%$ relative humidity and a 12:12 light:dark cycle. Upon arrival, animals were weighed and placed into polypropylene cages containing laboratory bedding (Sani-Chip Hardwood Bedding, PJ Murphy Forest Products, Inc.) that had been tested and was free of estrogen-like activity (Thigpen et al. 2013). Animals were randomly allocated to treatment groups; similar initial BW means in each group were maintained. Exogenous dietary estrogens were minimized by providing ad libitum access to AIN-93G (Harlan Laboratories) feed and RO/DI water, in bottles known to contain no estrogenic activity (Thigpen et al. 2013). All animals were treated humanely and in accordance with the approved protocols of the National Institute of Environmental Health Sciences Animal Care and Use Committee specific to this study.

Dosing of dams was based on daily BW. All chemicals were gavage administered to the animals by a trained technician. The technician was blinded to chemical/dose (color coded) and dams received chemical exposure by concealed allocation. Female offspring were followed for up to $16 \mathrm{mo}$. Any dam that produced litters with only males ( 1 control and $0.05 \mathrm{BPAF}$ ), or dams unable to care for her litter were excluded from all final analyses (one control).

\section{Experimental Design}

These studies were designed to provide $90 \%$ power to detect changes in pubertal indices, such as BW, vaginal opening ( 3-day difference), mammary development/score changes ( $\sim 0.5$ points $)$, 
and 2-fold changes in gene expression in female pups. Disposition studies in the pregnant CD-1 dam revealed that the bisphenol serum half-lives ranged from 4.5 to $7.0 \mathrm{~h}$, so to ensure that chemical steady state was reached and maintained; animals were dosed between 0700 and 0800 and then again about $7 \mathrm{~h}$ later, at the doses stated. Beginning on GD 10.5, just prior to formation of the rudimental mammary epithelial bud, timed pregnant dams were gavaged twice daily (BID) with BPA $50(n=11), 5(n=12)$, or $0.5 \mathrm{mg} / \mathrm{kg} \mathrm{BW}(n=13)$; BPAF $5(n=11), 0.5(n=11)$, or $0.05 \mathrm{mg} / \mathrm{kg} \mathrm{BW}(n=10) ;$ BPS 5 $(n=12), 0.5(n=11)$ or $0.05 \mathrm{mg} / \mathrm{kg} \mathrm{BW}(n=12)$; or vehicle control (pure sesame oil, $n=12$ ), in dose volumes of $10 \mu \mathrm{l} / \mathrm{g} \mathrm{BW}$. Dosing was completed on GD 17.5 because, in our experience (Hines et al. 2009; White et al. 2011; Tucker et al. 2015), this strain normally gives birth between GD 18.5 and GD 19. The vehicle control group served as the common control group for all three compounds, and all groups were represented concomitantly. Nontreatment related experimental conditions were identical across all study groups. The BPA dose range was based on a low observed adverse effect level (LOAEL) of $50 \mathrm{mg} \mathrm{BPA} / \mathrm{kg}$, a no observed adverse effect level (NOAEL) of $5 \mathrm{mg} / \mathrm{kg}$ for BPA, and the reference dose currently set by the U.S. EPA, which is $0.05 \mathrm{mg} \mathrm{BPA} / \mathrm{kg} / \mathrm{d}$ (U.S. EPA 2010; WHO 2009).

Exposure to BPA at concentrations lower than the reference dose set by the U.S. EPA has resulted in abnormal mammary gland development during critical periods of development in several rodent models (Durando et al. 2007; Moral et al. 2008; Vandenberg et al. 2008); however, there was no data to suggest an effective dose range for either BPAF or BPS. Therefore, the BPS and BPAF dose range that included the BPA reference dose concentration $(50 \mu \mathrm{g} / \mathrm{kg} ; 0.05 \mathrm{mg} / \mathrm{kg}$ BPAF and BPS) was chosen to estimate the low-level response in the mammary gland, and the upper end of treatment considered several studies that suggested estrogenic potential of these two analogues at doses lower than that of BPA (Matsushima et al. 2010). These doses, ending at a level 10 times less than the highest BPA dose, were also chosen because we anticipate that potential exposure to these chemicals in humans may be lower than BPA exposure. A summary of the experimental design is shown in Figure 1.

Parturition occurred on the eve of GD 18.5, and the next day was considered PND 1. Litters were culled to 10 pups at PND 3; a minimum of 5 females were retained to ensure that there were a sufficient number for analyses. In cases where there were $\geq 10$ females in a litter, no males were retained. Female offspring were assessed for pubertal maturation as detailed below and were weaned at PND 21. Randomly chosen females at PND 20, 28, 35, and 56 (1 per litter) and 3, 8, and 14 months (mostly 1, but sometimes 2 per litter) were weighed and euthanized by swift decapitation to obtain trunk blood for serum analysis and mammary glands for RNA, whole mount, and/or histopathological analysis. Between 11 and 13 months, unscheduled necropsies were performed because animals became moribund, the results of which triggered a necropsy of remaining animals at 14 months. Females were euthanized approximately $1-2 \mathrm{~h}$ following a confirmed estrus (for time points prior to 14 months) or diestrus smear (at 14-16 months; necropsied >14 months when exhibiting abnormal cycles), and within $4 \mathrm{~h}$ of lights on, to minimize effects of hormonal fluctuation. Necropsy usually occurred between 0900 and 1100. Data from mice necropsied at 3, 8, and 14 months were reported herein, but accounting of all animals was made in Table S1.

\section{Mammary Gland Preparation and Analysis}

The fourth and fifth inguinal mammary glands were removed and processed for whole mounts, and contralateral glands were fixed in $10 \%$ neutral buffered formalin (Fisher Scientific) for histopathology. Fixed glands were embedded in paraffin and cut into $5-\mu \mathrm{m}$ sections for hematoxylin and eosin (H\&E) staining or immunohistochemistry. Whole mounts were prepared by flattening glands on a charged slide for $1 \mathrm{~h}$, followed by fixation in Carnoy's solution overnight, rinsing in $70 \%$ ethanol and transitioning to water, staining with carmine alum $(2 \mathrm{~g} / \mathrm{L}$ carmine and $5 \mathrm{~g} / \mathrm{L}$ aluminum potassium sulfate) overnight, rinsing in water, then increasing gradually to $100 \%$ ethanol, and finally defatting in xylene until visibly clear (Davis and Fenton 2013, Appendix). Qualitative and quantitative assessments were performed at PND 20 and 35, hallmark timepoints associated with weaning and puberty. Developmental scores were assigned separately by two individuals, using a scale from 1-4 (1= poor development and 4 = best development) (Hilakivi-Clarke et al. 1997). Depending on age and level of development, scores were based on lateral and longitudinal epithelial growth, presence or absence of terminal end buds (TEBs), branching density, budding, and appearance of ductal ends. In whole mounts, TEBs were defined as ends that were $\geq 2 \mathrm{x}$ the diameter of its duct (Macon et al. 2011). Because the samples were compared with vehicle controls, the assessors were un-blinded to the vehicle control group, initially, and then they evaluated all glands within an age group blinded to treatment group.

Longitudinal growth, mammary epithelial area (MEA), duct length, and TEB count (Macon et al. 2011) were quantitatively measured using ImageJ (https://imagej.nih.gov/ij/). Glands were also quantitatively assessed for branching density using ImageJ and the modified Sholl analysis method (Stanko et al. 2015). A detailed visual description of this method is illustrated by Stanko and Fenton (Stanko and Fenton 2017). Briefly, images of glandular epithelium are skeletonized, binarized, dilated, and used to measure the MEA and longitudinal distance, defined as the most anterior position of the collecting duct to the most distal branch on the gland, using ImageJ. The total number of radial intersections (N) in the MEA was determined by Sholl analysis. The

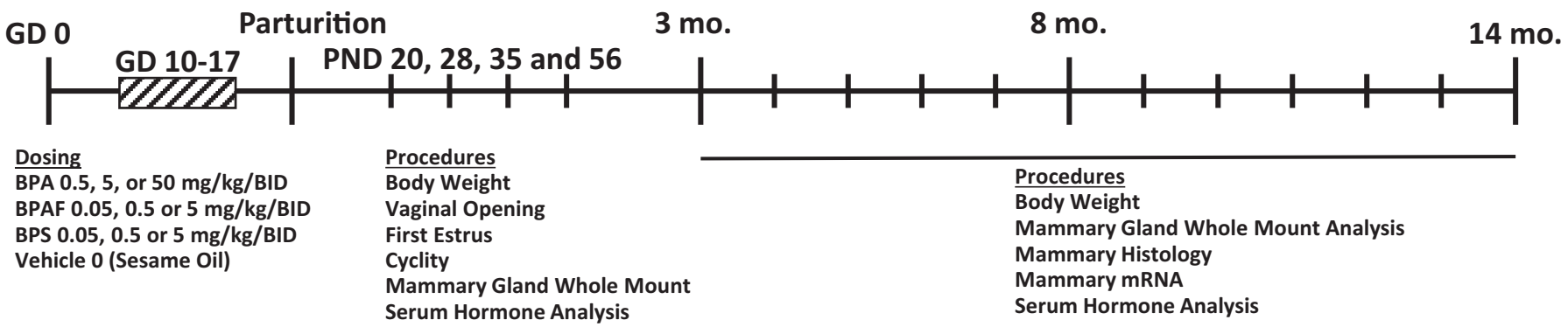

Figure 1. Study design summary. Time-pregnant mice were gavage dosed from gestation day (GD) 10.5 until 17.5 , twice daily (BID), with bisphenol A (BPA) $50(n=11), 5(n=12)$, or $0.5(n=13) \mathrm{mg} / \mathrm{kg}$ body weight $(\mathrm{BW})$; bisphenol AF (BPAF) $5(n=11,0.5(n=11)$, or $0.05(n=10) \mathrm{mg} / \mathrm{kg} \mathrm{BW}$; bisphenol S (BPS) $5(n=12), 0.5(n=11)$, or $0.05(n=12) \mathrm{mg} / \mathrm{kg} \mathrm{BW}$; or vehicle control (pure sesame oil, $n=12)$. Procedures were performed on various postnatal days (PND), including 3, 8, and 14 months. 
branching density of the gland was then calculated using the formula N/MEA. All quantitative measurements were performed on the fourth inguinal gland.

Numerous undifferentiated terminal ends, presumed to be TEBs, were noted upon examining whole mounts at 3 months, which is unusual for this age of CD-1 mice (S. Fenton, oral communication, June 2016). Therefore, all whole mounted glands were visualized by light microscopy (Leica Z16 APO, Leica Microsystems), terminal epithelial duct ends were measured and if greater than 2 times the diameter of the duct, they were recorded as a TEB. Whole mounts from 8- and 14-month-old mice were also examined for abnormalities (potential lesions) using light microscopy as described above. Unusual development was recorded. It should be noted that the Sholl method and certain quantitative measurements were unable to be performed on glands of animals $>3$ months old because of extensive growth and tissue density.

Contralateral fixed glands from mice of 3, 8, and 14 months old were embedded in paraffin, cut into 5 - $\mu \mathrm{m}$ sections, stained with H\&E, visualized on an Olympus BX41 (Olympus Scientific Solutions Americas Corp.) and digitally captured on an Olympus DP70 camera. A board-certified veterinary pathologist (S.H.B.) evaluated all histopathology samples and was blind to treatment.

Neoplastic and nonneoplastic mammary lesions were diagnosed using standardized nomenclature proposed by the International Harmonization of Nomenclature and Diagnostic Criteria for Lesions in Rats and Mice (INHAND) (Rudmann et al. 2012). On occasions where a definitive diagnosis could not be made, a pathology peer review group was convened to resolve the diagnosis. Microscopic lesions were graded using a standard four-point scale of minimal, mild, moderate, and marked severity grade criteria (Rudmann et al. 2012), representing the extent of involvement and size within the tissue.

Subsequent to evaluation and image capture of whole mounts from 3-, 8-, and 14-month time points, it was noted that the whole mounts contained gross abnormalities that were often not noted in the single section from the contralateral gland. Therefore, all mammary gland whole mounts from these ages were sectioned to observe the cellular environment surrounding the abnormal lesion. A detailed description and a visual tutorial of this method have recently been published (Tucker et al. 2016, 2017). Briefly, mammary whole mounts were immersed in xylene overnight to remove excess Permount (Fisher Scientific) and allow for ease of removing tissue from the slide. Glands were halved at the midline, placed in cassettes, and processed in a succession of xylene and xylene:molten paraffin steps before final embedding. Glands were sectioned at $4 \mu \mathrm{m}$, stained with H\&E and evaluated using the same criteria as the contralateral glands, by the same pathologist. The sectioned whole mount samples from 3-month-old mice were also evaluated for presence of retained TEB or intraductal hyperplasia, as stated above for formalin-fixed, contralateral glands in those same animals.

\section{Detection and Monitoring of Puberty and Estrous Cycle}

Beginning on PND 16, all female offspring were checked daily for vaginal opening (VO) by trained observers, using the methods described in Goldman et al. (Goldman et al. 2007). Upon vaginal opening, lavage was conducted, using 1X PBS, pH 7.4 (Gibco), to determine the timing of first estrus and their estrous stage at VO. Morning lavage was continued and read daily until each animal exhibited estrus. Beginning when all animals had achieved $\mathrm{VO}$ and for the next $4 \mathrm{wk}$, soiled bedding from age-matched male control mice was collected into a homogenous mix and dispersed into all female cages weekly to circulate male urinary proteins known to promote cyclity. From PND 63 until PND 84, the same groups of females were reassessed for estrous cyclity by examining cytology using the above referenced methods (Goldman et al. 2007).

\section{Hormone Analysis}

Briefly, following trunk blood collection in a BD Vacutainer SST Plus tube (BD Bioscience), the blood was inverted and stored at room temperature for $30 \mathrm{~min}$. Samples were centrifuged at $1,100 \mathrm{~g}$ for $15 \mathrm{~min}$, and serum was collected in a fresh tube and stored at $-80^{\circ} \mathrm{C}$ until processing.

Serum preparation and analysis were performed per the manufacturer's protocols. Samples were run on a multiplex Steroid Hormone Panel Kit from Meso Scale Discovery (MSD) to determine estradiol, progesterone, testosterone, and dehydroepiandrosterone (DHEA) concentrations. Samples and standards were added to 96-well plates precoated with antibody and incubated for $2 \mathrm{~h}$ at room temperature. A SULFOTAG label tracer was added to each well, which generates a signal to determine the analyte concentration. The plates were washed three times with 1X PBS-T and after final wash, $150 \mu \mathrm{L}$ of a $1 \mathrm{X}$ Read-Buffer added to each well, and plates were immediately imaged on a Sector Imager 2,400 System (Meso Scale Discovery). All samples $(50 \mu \mathrm{L})$ were run in duplicate, on the same day. Standards for all hormones were supplied in the MSD reagent kit (lowest standards were $0.005,0.07$, and $2.7 \mathrm{ng} / \mathrm{ml}$ for estradiol, progesterone, and DHEA, respectively), except for testosterone (range $0.02 \mathrm{ng} / \mathrm{ml}-16 \mathrm{ng} / \mathrm{ml}$ ), which was purchased from Steraloids, Inc. The coefficient of variation varied from $2 \%$ (E2) to $11 \%$ (T) for the four assay endpoints.

\section{RNA Preparation}

RNA was extracted from frozen mammary tissue by homogenizing the gland with Trizol using Lysing D Matrix tubes (MP Biomedicals). Samples were homogenized in a MP Biomedical Fast Prep-24 SG at $6.0 \mathrm{~m} / \mathrm{sec}$ for 40-s intervals. Samples were homogenized a total of 2-3 times and placed on ice between each interval. Samples were transferred to a clean tube and centrifuged to remove debris and the lipid layer. RNA was isolated following the manufacturer's protocol. Samples underwent on-column DNAse I digestion using the RNA Mini Kit (Qiaqen). RNA quantity and integrity were measured on a Nano Drop 2000c (ThermoScientific) and Agilent Bioanalyzer. Samples with RNA integrity numbers $\geq 7.9$ were used for PCR. One microgram of RNA was reverse transcribed with the High Capacity cDNA Synthesis Kit (Applied Biosystems) using the MyCycler (BioRad Thermocycler, Hercules). Complimentary DNA was amplified with Taqman Universal PCR Master mix, No AmpErase UNG, with the following Taqman primers (Roche): Esrl (Mm00433149_m1), Pgr (Mm00435628_m1), Ar (Mm00442688_m1), Gper1 (Mm02620446_s1). Amplification was performed on a QuantStudio 7 Flex PCR (Applied Biosystems) and analyzed using QuantStudio Real-Time PCR Software and Microsoft Excel $^{\text {TM }} 2010$ (Microsoft Office Suite). Mean Ct values $\geq 35$ or with a standard deviation of $\geq 0.5$ between duplicates were not included in the final analyses. Cdknal was used as the housekeeping gene for all samples. All analyses were performed using the $2^{-\Delta \Delta \mathrm{Ct}}$ method and are illustrated as the fold change relative to vehicle control.

\section{Statistical Analysis}

Unless noted, all data are represented as mean \pm SEM. The dam was considered the unit of measurement. In nearly all cases, one pup per dam was sampled at any given time point. When multiple pups per dam were evaluated in the same analysis of quantitative endpoints, such as timing of $\mathrm{VO}$ and first estrus, mixed effects analysis of variance (ANOVA) with Dunnett's test was used to account for potential litter effects. TEB (or retained undifferentiated ends) occurrence was statistically evaluated using one-sided Cochran-Armitage trend tests. ANOVA with Dunnett's multiple 
comparisons test was applied to quantitative endpoints for which one pup per litter was assessed. The Mann-Whitney test was used to compare chemical dose group to control for Sholl analysis and mammary gland quantitative measurements. Onesided Jonckheere's test (SAS/STAT ${ }^{\circledR} 9.2$ User's Guide) was performed to determine dose-related trends. Hormone measurements were log transformed prior to statistical analyses to improve normality. Mean severity scores were calculated for 3-, 8-, and 14-month lesions whenever applicable, and one-sided Fisher's exact tests were performed to compare lesion incidences in each dose group with the vehicle control group. CochranArmitage tests (SAS/STAT ${ }^{\circledR} 9.2$ User's Guide) were used to analyze for trends across dose groups. All analyses were performed using SAS 9.3 by G.E.K. All Graphs and tables were generated using Microsoft Excel ${ }^{\mathrm{TM}}$ and GraphPad Prism, and statistical significances were denoted at $p \leq 0.05$.

\section{Results}

\section{Female Offspring BW}

Body weight was assessed in vehicle, BPA, BPAF, or BPS prenatally exposed female offspring necropsied on PND 20, 28, 35, and 56 and at 3, 8, and 14 months (Figure S1). Few differences among doses within a treatment group were observed; at PND 35, the BPAF $0.5 \mathrm{mg} / \mathrm{kg}$ group was significantly smaller in comparison with controls and transitioned back to control-comparable weight by PND 56. Necropsied females at PND 56 in the $5 \mathrm{mg} \mathrm{BPS} / \mathrm{kg}$ BW dose group were approximately 6 grams smaller than controls $(17 \% ; p<0.05)$. At 3,8 , and 14 months, no significant differences were observed between any exposure group and the vehicle control group.

\section{Pubertal Assessment}

Females were assessed for timing of pubertal development, including age at $\mathrm{VO}$ and first estrus, and mammary development. The average age of $\mathrm{VO}$ was between 25 and $27 \mathrm{~d}$ old in all treatment groups, with no significant differences observed among the groups (Figure 2A). Similarly, time to first estrus in BPA-, BPAF-, or BPS-exposed groups did not differ significantly from that of the vehicle control group and occurred at a mean age of 27-28 d old (Figure 2B). Estrous cyclity was monitored for three consecutive weeks between PND 63-83. The number of normal estrous cycles (3-4 d) for each exposed group and the vehicle controls were not significantly different (Table S2).

\section{Pubertal Mammary Gland Development}

Even though there was no effect on VO or estrous cyclicity, prenatal exposure to BPA, BPAF, or BPS significantly influenced development of the mammary gland in female offspring evaluated on PND 20 using quantitative criteria (Figure 3). Specifically, mammary glands from females in the BPAF groups exhibited greater longitudinal growth (Figure 3A) and branching density (and sum of intersections; Figure 3B and 3C), higher TEB counts, and more $\mathrm{TEB} / \mathrm{mm}^{2}$ (Figure $3 \mathrm{D}$ and $3 \mathrm{~F}$ ). Trend tests revealed a significant relationship between increasing concentration of BPAF and effects on sum of intersections, and treatment with both BPAF and BPS resulted in a significantly higher TEB:Length and TEB Count, in a dose-related manner (Figure 3B, D and F). Control glands averaged $\sim 2$ TEB/gland on PND 20, whereas animals in the BPA $5 \mathrm{mg} / \mathrm{kg}$, BPAF 0.05 and $5 \mathrm{mg} / \mathrm{kg}$, and BPS $5 \mathrm{mg} / \mathrm{kg}$ groups averaged close to $10 \mathrm{TEB} /$ gland (Figure 3F). Significant differences in mammary epithelial branching density were also measured between control vs. exposed groups (BPA $0.5 \mathrm{mg} / \mathrm{kg}$, BPAF
A

B P A

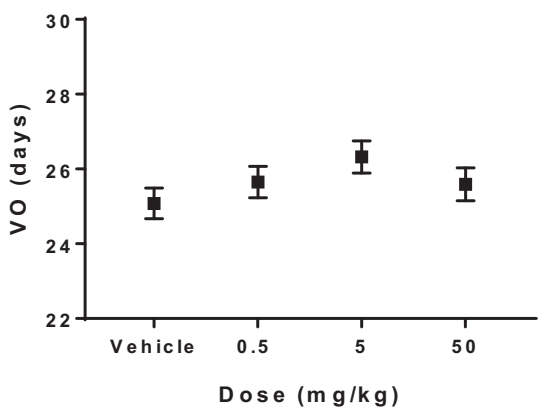

$\mathrm{B}$

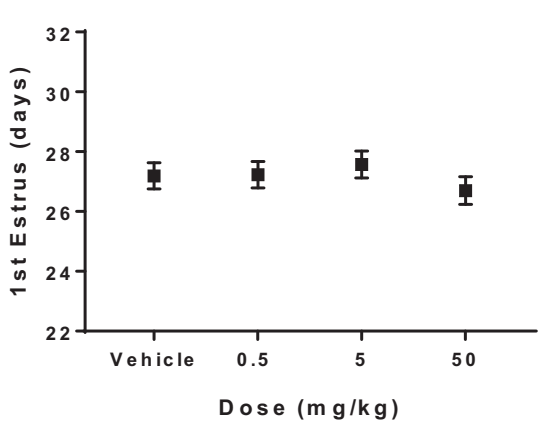

B P A F

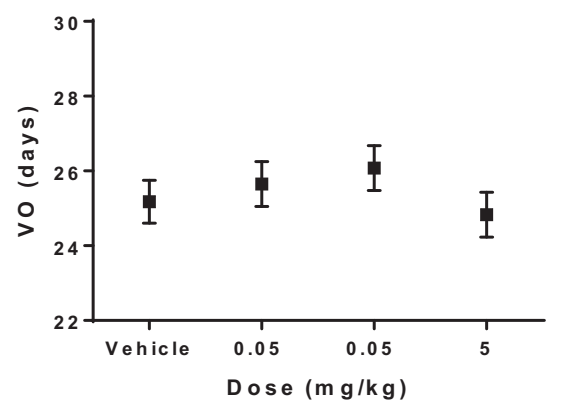

B P A F

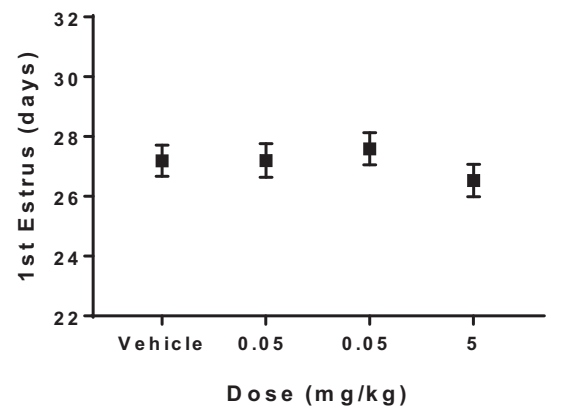

B P S

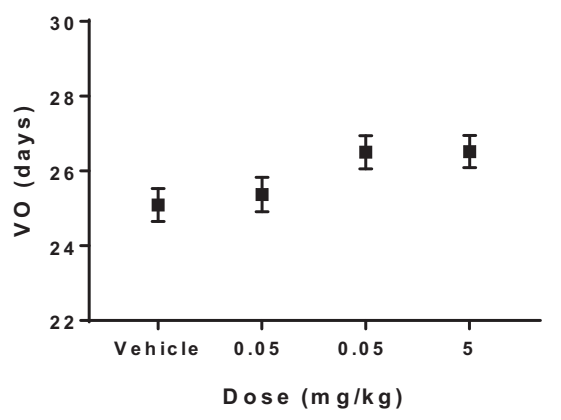

B P S

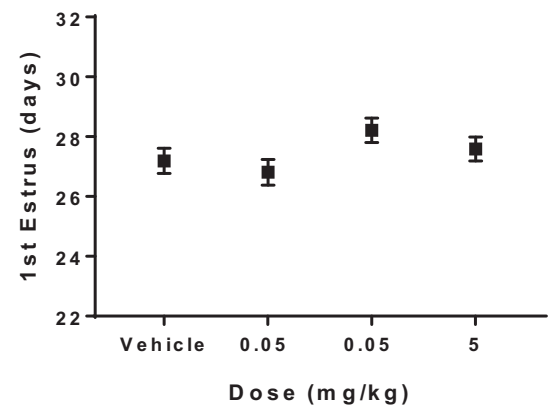

Figure 2. Pubertal assessment in CD-1 female offspring prenatally exposed to bisphenol A (BPA), bisphenol AF (BPAF), or bisphenol S (BPS). Data are reported as mean age with standard error bars (days old) at $(A)$ Vaginal opening (VO) and $(B)$ Occurrence of first estrus for the various doses of bisphenols. No statistical differences were observed when bisphenol-exposed animals were compared with vehicle controls using mixed effects ANOVA, with a Dunnett's post-hoc test. Number of animals per group is noted in Table 1. 
A

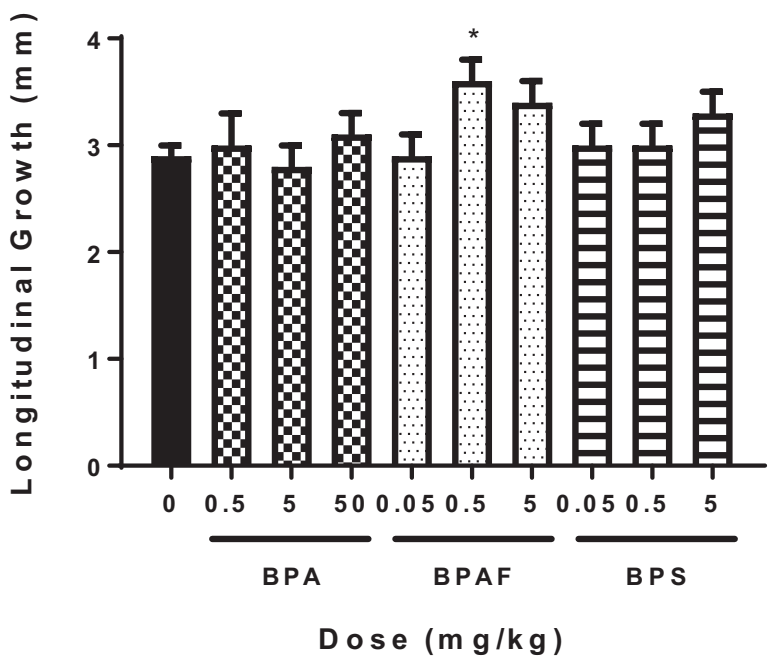

$\mathrm{C}$

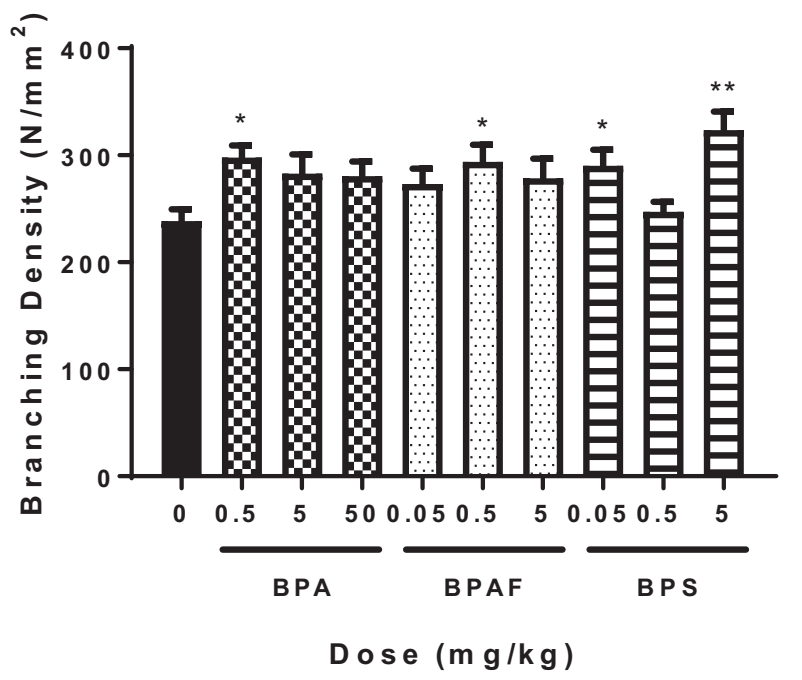

E

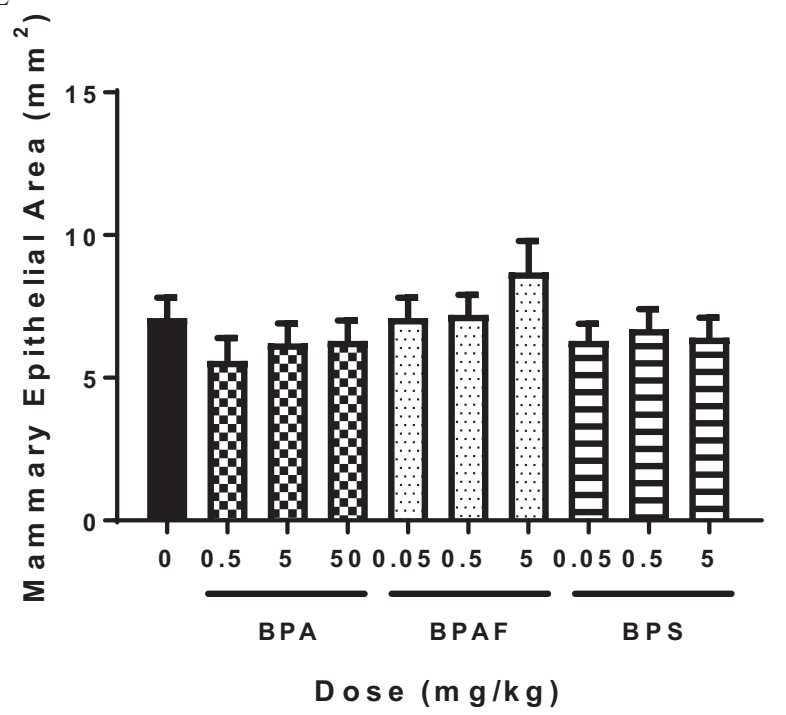

B

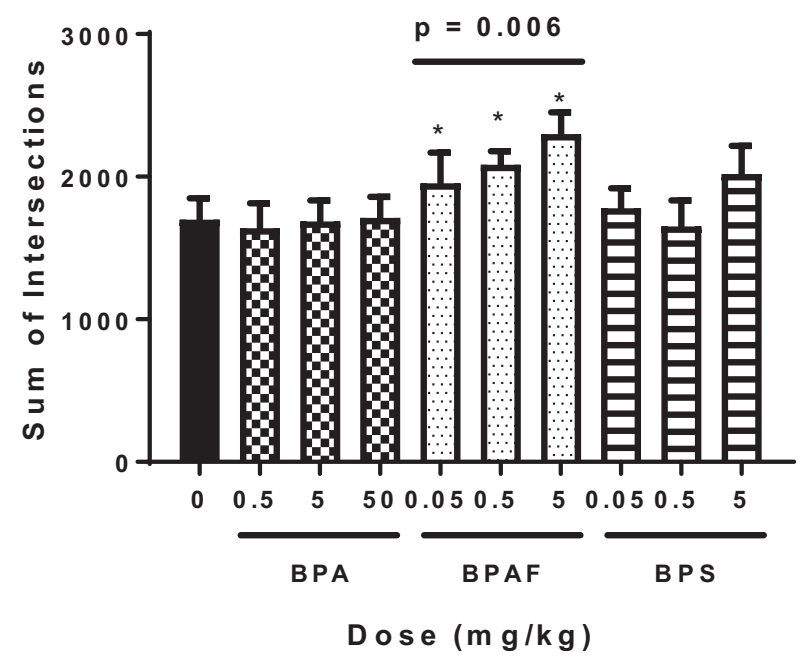

D

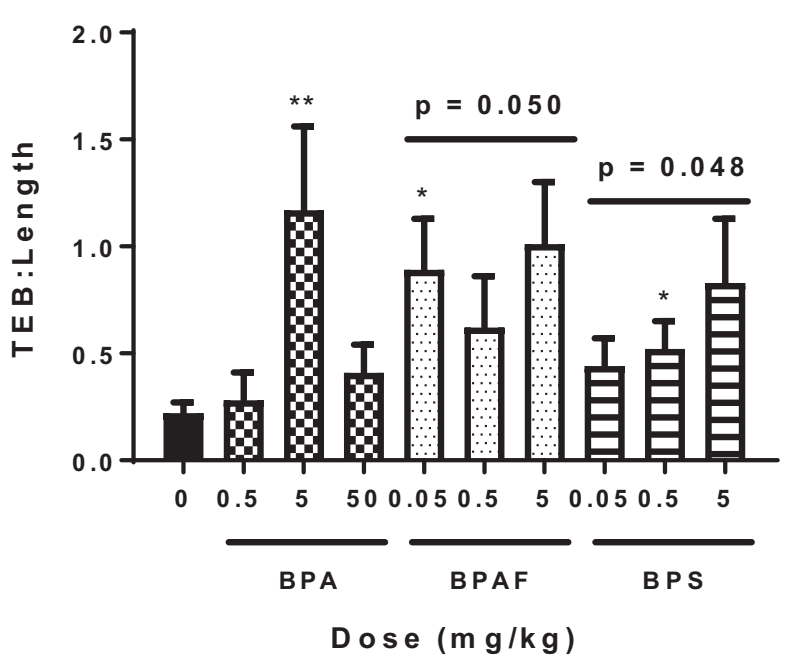

F

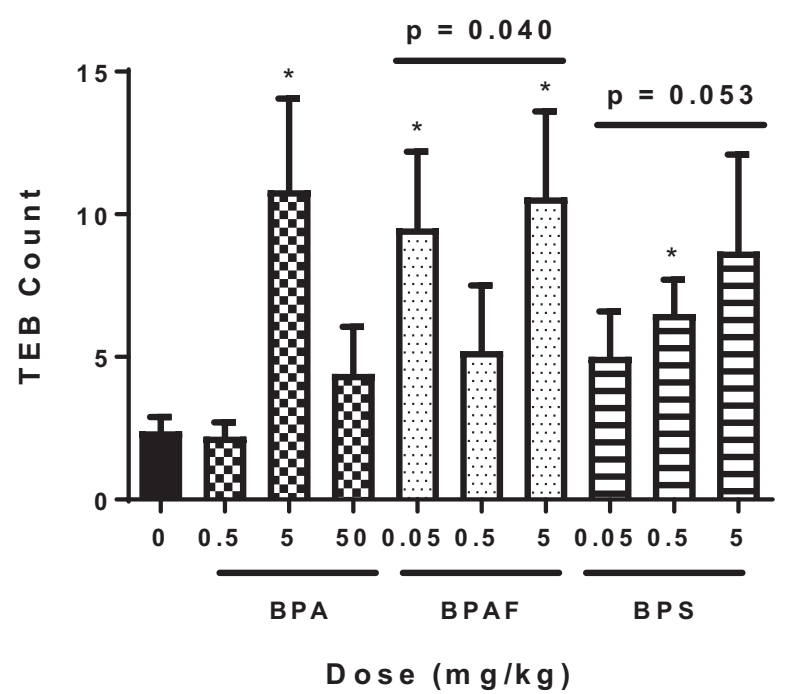

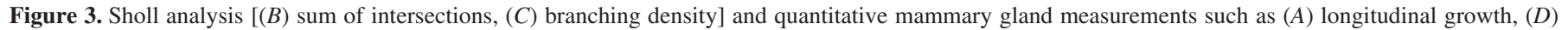

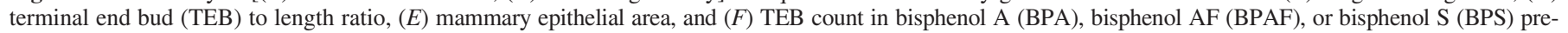

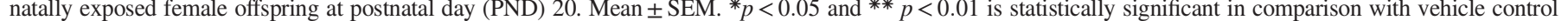

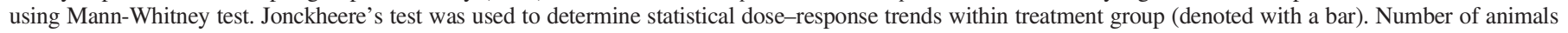
per group is noted in Table 1 . 
Table 1. Pubertal mammary gland development scores of female offspring exposed in utero to bisphenol A (BPA), bisphenol AF (BPAF), and bisphenol S (BPS).

\begin{tabular}{|c|c|c|c|c|}
\hline Exposure $(\mathrm{mg} / \mathrm{kg})$ & PND $20(n)$ & PND $28(n)$ & PND 35 (n) & PND $56(n)$ \\
\hline Vehicle & $2.03 \pm 0.07(8)$ & $2.33 \pm 0.18(6)$ & $1.92 \pm 0.21(5)$ & $2.39 \pm 0.15(9)$ \\
\hline BPA 0.5 & $2.41 \pm 0.12(10)$ & $3.00 \pm 0.25(6)$ & $2.50 \pm 0.33(9)$ & $3.00 \pm 0.12(8)$ \\
\hline BPA 5 & $2.79 \pm 0.22(10)^{* * * *}$ & $1.92 \pm 0.22(6)$ & $2.46 \pm 0.22(6)$ & $2.79 \pm 0.26(6)$ \\
\hline BPA 50 & $2.45 \pm 0.23(10)$ & $2.50 \pm 0.26(8)$ & $2.89 \pm 0.21(7)^{*}$ & $3.11 \pm 0.22(7)$ \\
\hline BPAF 0.05 & $2.77 \pm 0.27(8)^{* *}$ & $2.79 \pm 0.33(6)$ & $3.12 \pm 0.35(6)^{*}$ & $2.95 \pm 0.17(5)$ \\
\hline BPAF 0.5 & $2.79 \pm 0.19(9)^{* * * *}$ & $2.57 \pm 0.18(7)$ & $1.96 \pm 0.18(6)$ & $2.78 \pm 0.28(8)$ \\
\hline BPAF 5 & $2.80 \pm 0.17(10)^{* * *}$ & $3.25 \pm 0.23(7)^{*}$ & $3.05 \pm 0.46(5)^{*}$ & $2.93 \pm 0.37(7)$ \\
\hline BPS 0.05 & $2.44 \pm 0.14(10)$ & $2.75 \pm 0.22(8)$ & $3.21 \pm 0.23(6)^{* *}$ & $2.96 \pm 0.34(7)$ \\
\hline BPS 0.5 & $2.38 \pm 0.19(10)$ & $2.38 \pm 0.19$ & $3.00 \pm 0.23(8)^{* *}$ & $3.22 \pm 0.22(8)^{*}$ \\
\hline BPS 5 & $2.69 \pm 0.24(10)^{* *}$ & $3.04 \pm 0.20(6)$ & $2.88 \pm 0.23(8)^{*}$ & $2.61 \pm 0.21$ \\
\hline
\end{tabular}

Note: Evaluations on postnatal days (PND) 20-56 demonstrate advanced glandular development in bisphenol-exposed animals. Glands are scored on a scale of 1 (poor development) to 4 (best development) by two individuals blind to group allocation. There was a common vehicle control group for all chemicals. Data are presented as the mean \pm SEM. Dam is the unit of measurement. Litter number $=n(1$ animal/litter/time point $)$. Significantly different from the control group by Dunnett's post-hoc test at $* p<0.05 ; * * p<0.01 ; * * * p<0.001$

$0.5 \mathrm{mg} / \mathrm{kg}$, and BPS 0.05 and $5 \mathrm{mg} / \mathrm{kg}$; Figure 3C) using the Sholl analysis (Stanko et al. 2015). Mammary epithelial area (an indication of lateral and longitudinal growth) in the exposed groups did not differ significantly from the vehicle control group.

Qualitative developmental scoring predicted these quantitative findings on PND 20. BPA $5.0 \mathrm{mg} / \mathrm{kg}$ and BPS $5.0 \mathrm{mg} / \mathrm{kg}$ exposed groups had significantly higher developmental scores than controls suggesting an overall accelerated phenotype (Table 1). All BPAF treated dose groups exhibited significantly accelerated mammary gland development when assessed via developmental scoring (Table 1), and this development is attributed to the increased number of TEBs (shown as arrowheads in Figure 4, top panel) and branching points (Figures 3B, D and F).

By PND 35, the BPA $50 \mathrm{mg} / \mathrm{kg}$, BPAF 0.05 and $5 \mathrm{mg} / \mathrm{kg}$, and every BPS exposed group exhibited developmental scores that were significantly higher than those of the vehicle control group (Table 1). In comparing vehicle control whole mounts to BPSexposed glands on PND 35, TEBs were visually apparent in the leading edges of $100 \%$ of control glands; however, as BPS exposure dose increased, the distance between the fourth and fifth glands decreased, and many had grown together $(5.0 \mathrm{mg} / \mathrm{kg}$ BPS; shown as arrows Figure 4, bottom panel). It was also visually noted that epithelial growth had either approached or surpassed the lymph node (LN in Figure 4), something that was observed in few control glands. These visual landmarks were not quantitatively measured but were taken into consideration when generating blinded developmental scores. When glands were evaluated three weeks later (PND 56), the control and low doses of all treatment groups had caught up to the accelerated pace of growth and development seen in bisphenol-exposed mice at earlier ages, and only BPS $0.5 \mathrm{mg} / \mathrm{kg}$ group still exhibited an advanced mammary phenotype because of enhanced branching density (Table 1).

\section{Latent Effects in the Mammary Gland}

Mammary gland whole mounts and histological sections from female offspring were also evaluated in early, mid, and late adulthood to determine the spontaneous occurrence and incidence of mammary lesions following prenatal exposure to BPA, BPAF, or BPS. When evaluating the whole mounts at 3 months of age, undifferentiated terminal duct ends were apparent on the leading edge of the fourth gland in approximately $41-75 \%$ of mammary glands in each of the exposed groups (exception is BPAF $5 \mathrm{mg} / \mathrm{kg}$ group, $14 \%$ ) in comparison with only $25 \%$ of vehicle control glands (Figure 5). Differences in undifferentiated duct end occurrence were not statistically significant using apparent vs. none criterion.
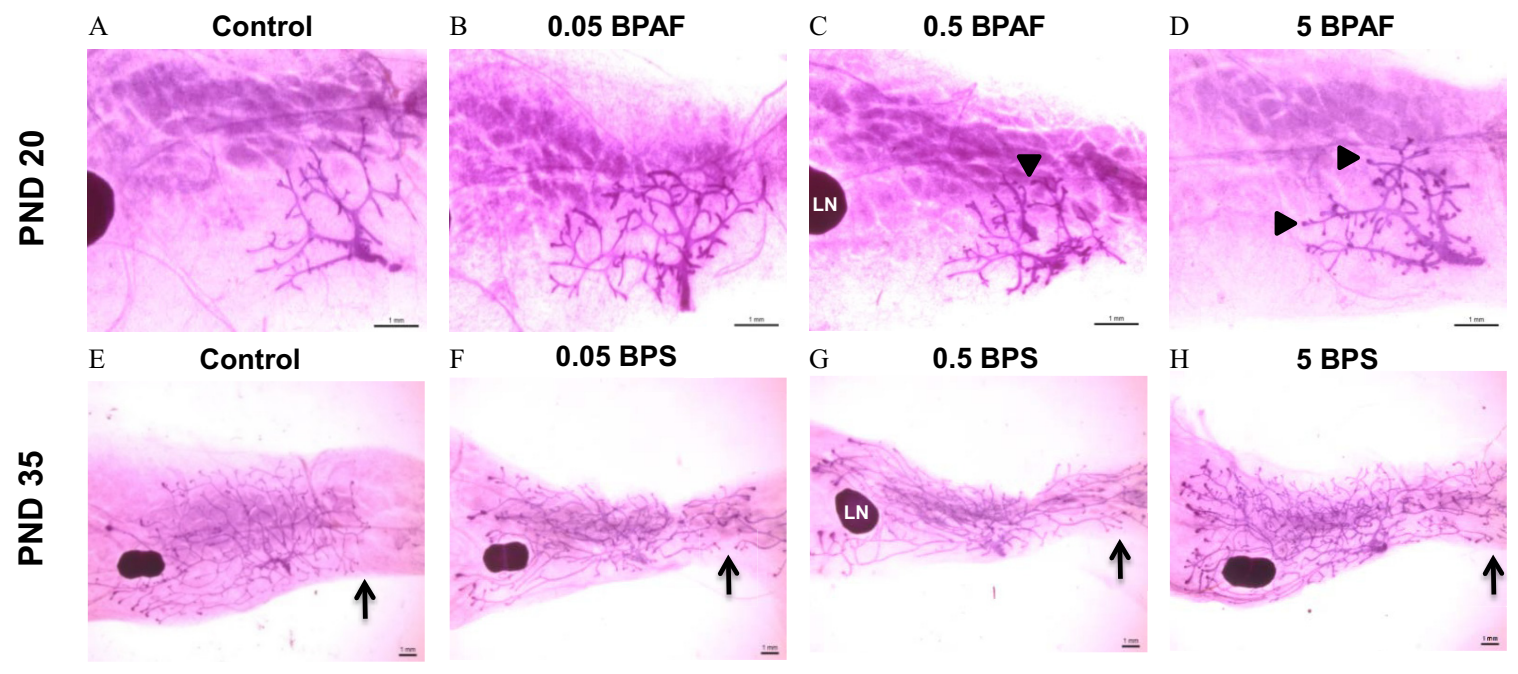

Figure 4. Representative mammary gland whole mounts from bisphenol AF (BPAF)-exposed females on postnatal day (PND) 20 (top panel) and bisphenol S (BPS)-exposed females on PND 35 (bottom panel). Each image represents the mean scores shown in Table 1 for these ages/dose groups. (A) and $(E)$ Vehicle Control; (B) BPAF $0.05 \mathrm{mg} / \mathrm{kg}$; $(C)$ BPAF $0.5 \mathrm{mg} / \mathrm{kg} ;(D)$ BPAF $5 \mathrm{mg} / \mathrm{kg}$, (F) BPS $0.05 \mathrm{mg} / \mathrm{kg}$; $(G)$ BPS $0.5 \mathrm{mg} / \mathrm{kg}$; and $(H)$ BPS $5 \mathrm{mg} / \mathrm{kg}$. Scale bar $=1 \mathrm{~mm}(\mathrm{~A}-\mathrm{H})$. Arrowheads denote terminal end buds increased in mid- and high-dose BPAF groups, LN $=$ lymph nodes, and arrows indicate the area of the fat pad in which the fourth and fifth glands typically meet. BPS-treated animals demonstrated precocious epithelial growth, and fourth and fifth gland ends met sooner than controls. Number of animals per group is noted in Table 1. 

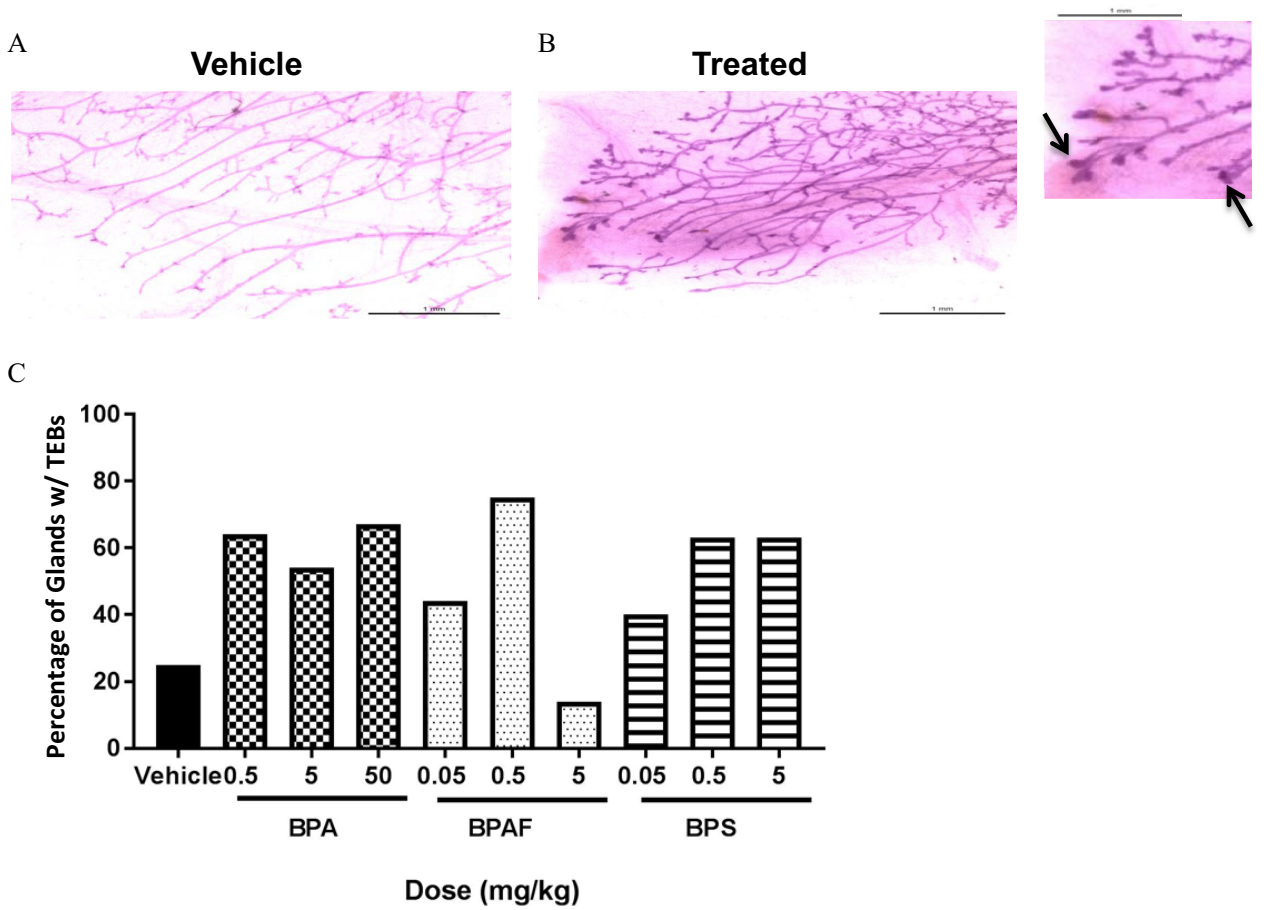

Figure 5. Occurrence of terminal end buds (TEBs) in mammary glands of 3-mo old females prenatally exposed to bisphenol A (BPA), bisphenol AF (BPAF), or bisphenol S (BPS). Representative images shown are A) Control and B) $0.5 \mathrm{mg} / \mathrm{kg}$ bisphenol AF (BPAF)-exposed mammary whole mounts. Inset: Arrows represent putative TEBs retained at 3 months in BPAF-exposed mammary gland. Scale bar $=1 \mathrm{~mm}$ (A-B, inset). C) Occurrence of retained TEBs was determined as a percentage of total animals in each dose group (apparent/none) with TEBs. Vehicle $(n=8)$, BPA $0.5(n=11)$, BPA $5(n=11)$, BPA $50(n=9)$, BPAF $0.05(n=9)$, BPAF $0.5(n=8)$, BPAF $5(n=7)$, BPS $0.05(n=10)$, BPS $0.5(n=8)$, and BPS $5(n=8)$.

As it is uncommon to see retained undifferentiated duct ends in 3month-old CD-1 mice, more than $50 \%$ of the whole mounts from each treatment group, including those containing putative TEBs, and all control glands were removed from slides and sectioned. We aimed to determine if the undifferentiated duct ends were TEBs and if they were typical, or exhibited atypia. TEB were visible in sectioned tissues of treated, but not control animals and were considered to be within normal range (not preneoplastic); however the pathologist noted that half the animals in the BPS $0.5 \mathrm{mg} / \mathrm{kg}$ group had increased TEB (see Table 2). The contralateral glands, which had been processed for H\&E at necropsy, were also void of preneoplastic lesions.

Table 2. Mammary gland whole mount evaluation results in 3-month-old mice.

\begin{tabular}{lccc}
\hline $\mathrm{Mg} / \mathrm{kg}$ dose of bisphenol & $\begin{array}{c}\text { NSF } n \\
\text { (\% of total) }\end{array}$ & $\begin{array}{c}\text { Any diagnosis } n \\
\text { (\% of total) }\end{array}$ & $p$-value \\
\hline 0 BPA $(n=8)$ & $7(87.5 \%)$ & $1(12.5 \%)$ & $\mathbf{0 . 0 0 3}$ \\
0.5 BPA $(n=11)$ & $11(100 \%)$ & $0(0 \%)$ & 1.000 \\
5 BPA $(n=11)$ & $10(90.9 \%)$ & $1(9.1 \%)$ & 0.836 \\
50 BPA $(n=9)$ & $5(55.6 \%)$ & $4(44.4 \%)$ & 0.183 \\
0 BPAF $(n=8)$ & $7(87.5 \%)$ & $1(12.5 \%)$ & 0.119 \\
0.05 BPAF $(n=9)$ & $6(66.7 \%)$ & $3(33.3 \%)$ & 0.335 \\
0.5 BPAF $(n=8)$ & $7(87.5 \%)$ & $1(12.5 \%)$ & 0.767 \\
5 BPAF $(n=7)$ & $4(57.1 \%)$ & $3(42.9 \%)$ & 0.231 \\
0 BPS $(n=8)$ & $7(87.5 \%)$ & $1(12.5 \%)$ & 0.190 \\
0.05 BPS $(n=9)$ & $8(88.9 \%)$ & $1(11.1 \%)$ & 0.794 \\
0.5 BPS $(n=9)$ & $3(33.3 \%)$ & $6(66.7 \%)$ & $\mathbf{0 . 0 3 6}$ \\
5 BPS $(n=9)$ & $8(88.9 \%)$ & $1(11.1 \%)$ & 0.794 \\
\hline
\end{tabular}

Note: NSF, no significant finding. $n=$ no. litters represented. Bisphenol A (BPA), bisphenol AF (BPAF), and bisphenol S (BPS). Any Diagnosis = inflammation or increased TEB; some animals had both diagnoses. Inflammation $=$ mixed cell inflammation of all severities, Increased TEB $=$ increased terminal end buds, all severities.

${ }^{a}$ Treated vs. control was evaluated by Fisher's exact test; significant trend for doseresponse by Cochran-Armitage test is shown in control column; $P<0.05$. Bolded values were significant in these tests.
In addition to retained TEB, mixed cell inflammation was noted in the sectioned tissues of 3-month-old mice (Table 2), although no gross lesions were evident in reviewing the whole mounts prior to sectioning. Mixed cell inflammation was characterized by lymphocytes, plasma cells, macrophages, and low numbers of neutrophils located within the adipose tissue of the mammary gland. Mixed cell inflammation was diagnosed in one animal from the control group and in at least one animal from several of the exposed groups (BPA 5 and $50 \mathrm{mg} / \mathrm{kg}$, BPS 0.5 and $5 \mathrm{mg} / \mathrm{kg}$, and all doses of BPAF; Table 3). However, there was a significant dose trend for more abnormalities in the BPA-exposed animals (44\% with a diagnosis in high dose group) and significantly higher incidence of diagnoses in the BPS $0.5 \mathrm{mg} / \mathrm{kg}$ dose group (25\% exhibited inflammation, and 50\% had increased TEB; Table 2).

Inflammation (lymphoplasmacytic, perivascular, and/or mixed cell inflammation) was the only finding observed in the control mammary glands evaluated in this study (from 3 to 14 months of age), present in 3 of 26 animals ( $11.5 \%$ incidence, Table 3; one 14-month-old animal had both diagnoses). Inflammation was the most common finding observed in the prenatally exposed adult mammary glands with $26 \%$ (69/266) of the animals diagnosed with inflammation with or without a proliferative lesion (lobuloalveolar hyperplasia or adenocarcinoma). The total number of animals affected included those euthanized early because of various morbidities or were found dead (summarized in Table S1). Bisphenolexposed animals $\geq 14$ months old had the highest incidence of inflammation [ $\sim 53 \%$ of all cases; Table 3 (14 months old) and Table S1 (all animals)].

In animals necropsied at 14 months of age, the BPS $0.5 \mathrm{mg} / \mathrm{kg}$ group had a statistically higher incidence of perivascular lymphoplasmacytic inflammation than controls (Table 3; represented in Figure 6D). The BPAF-exposed animals exhibited a greater incidence of mixed cell inflammation than control animals, with a significant dose trend noted (Table 3). When all types of 
Table 3. Mammary gland lesion incidences by age and treatment group following prenatal exposure to bisphenol A (BPA), bisphenol AF (BPAF), and bisphenol S (BPS).

\begin{tabular}{|c|c|c|c|c|c|c|c|c|c|c|}
\hline \multirow[b]{2}{*}{ Lesion development } & \multirow{2}{*}{$\frac{\text { Vehicle }}{0}$} & \multicolumn{3}{|c|}{$\mathrm{BPA}(\mathrm{mg} / \mathrm{kg})$} & \multicolumn{3}{|c|}{$\mathrm{BPAF}(\mathrm{mg} / \mathrm{kg})$} & \multicolumn{3}{|c|}{$\mathrm{BPS}(\mathrm{mg} / \mathrm{kg})$} \\
\hline & & $\overline{0.5}$ & 5 & 50 & $\overline{0.05}$ & 0.5 & 5 & $\overline{0.05}$ & 0.5 & 5 \\
\hline 3 months (n) & 8 & 11 & 11 & 9 & 9 & 8 & 7 & 9 & 9 & $\overline{9}$ \\
\hline Inflammation, mixed cell & 1 & 0 & 1 & 3 & 1 & 1 & 2 & 0 & 2 & 1 \\
\hline 8 months (n) & 5 & 8 & 5 & 5 & 7 & 5 & 6 & 3 & 5 & 5 \\
\hline Lobuloalveolar hyperplasia & 0 & 0 & 1 & 0 & 0 & 0 & 0 & 0 & 0 & 0 \\
\hline Inflammation, mixed cell & 0 & 0 & 0 & 0 & 0 & 0 & 1 & 0 & 0 & 0 \\
\hline Squamous metaplasia, ductal & 0 & 0 & 0 & 0 & 0 & 0 & 1 & 0 & 0 & 0 \\
\hline 14 months (n) & 13 & 14 & 11 & 6 & 14 & 18 & 22 & 11 & 18 & 13 \\
\hline Carcinoma & 0 & 0 & 0 & 0 & 0 & 0 & 0 & 0 & 2 & 0 \\
\hline Fibroadenoma & 0 & 0 & 0 & 0 & 0 & 0 & 0 & 0 & 0 & 1 \\
\hline Histiocytic sarcoma & 0 & 0 & 0 & 0 & 0 & 0 & 0 & 0 & 1 & 0 \\
\hline Lipoma & 0 & 0 & 1 & 0 & 0 & 0 & 1 & 0 & 0 & 0 \\
\hline Cyst & $0^{\dagger}$ & 0 & 0 & 0 & 0 & 1 & 3 & 1 & 1 & 0 \\
\hline Duct dilation & 0 & 0 & 0 & 1 & 0 & 0 & 0 & 0 & 0 & 0 \\
\hline Hemorrhage, focally extensive & 0 & 0 & 0 & 1 & 0 & 0 & 0 & 0 & 0 & 0 \\
\hline Inflammation, Lymphoplasmacytic perivascular & 2 & 5 & 3 & 3 & 7 & 7 & 5 & 2 & $11^{*}$ & 3 \\
\hline Inflammation, mixed cell & $1^{\text {本 }}$ & 0 & 0 & 0 & 1 & 2 & 8 & 2 & 6 & 2 \\
\hline Inflammation, neutrophilic & 0 & 0 & 0 & 0 & 0 & 0 & 1 & 0 & 0 & 0 \\
\hline Inflammation, not specified & 0 & 0 & 0 & 0 & 0 & 0 & 1 & 0 & 0 & 0 \\
\hline Keratin & $0^{\S}$ & 0 & 0 & 0 & 1 & 0 & 1 & 0 & 0 & 1 \\
\hline Lobuloalveolar hyperplasia & $0^{\ddagger}$ & 3 & 2 & 1 & 0 & 1 & 5 & 0 & $5 *$ & 1 \\
\hline Lymph node: inflammation, neutrophilic & 0 & 0 & 0 & 0 & 0 & 0 & 0 & 0 & 1 & 0 \\
\hline Lymph node: Inflammation, mixed with eosinophilic crystals & 0 & 0 & 0 & 0 & 0 & 0 & 0 & 0 & 0 & 1 \\
\hline Lymph node: squamous cell carcinoma or met from Zymbal's gland & 0 & 0 & 0 & 0 & 0 & 0 & 1 & 0 & 1 & 0 \\
\hline Lymph node: vascular angiectasis & 0 & 0 & 0 & 0 & 0 & 0 & 0 & 0 & 1 & 0 \\
\hline Lymph node: increased cellularity, plasma cells & 0 & 0 & 0 & 0 & 0 & 0 & 1 & 0 & 0 & 0 \\
\hline Papillary hyperplasia, multifocal & 0 & 0 & 0 & 0 & 0 & 0 & 0 & 0 & 1 & 0 \\
\hline Squamous metaplasia, ductal & $0^{\ddagger}$ & 0 & 0 & 0 & 1 & 2 & $7 *$ & 1 & 4 & 1 \\
\hline
\end{tabular}

Note: Six moribund animals necropsied between 11 and 12 months also displayed mixed cell inflammation (BPA: 5 and 50, BPAF: 0.05 and 0.5 , and BPS 0.05 and 5 mg/kg) and are represented in Table $\mathrm{S} 1$.

* Significantly differs from the control group by Fisher's exact test at $p<0.05$.

Significant dose trends are shown in control columns:

Significant trend for BPAF by the Cochran-Armitage trend test at $p<0.05$;

${ }^{+}$Significant trend for BPAF by the Cochran-Armitage trend test at $p<0.01$.

${ }^{8}$ Significant trend for BPS by the Cochran-Armitage trend test at $p<0.05$.

inflammation (perivascular and mixed cell inflammation) were combined (Table 4), and multiple diagnoses were controlled for, there were significantly more inflammation diagnoses in the BPAF $5 \mathrm{mg} / \mathrm{kg}$ group in comparison with controls. The lowest BPAF exposure group also exhibited a strong inflammatory response that did not reach significance $(p=0.08)$, and this resulted in a dose-related trend in inflammation in the BPAF group, although this difference did not reach significance $(p=0.06)$. Significantly more inflammation diagnoses in comparison with the control group were also evident in the BPS $0.5 \mathrm{mg} / \mathrm{kg}$ group.

As early as 8 months of age, nonneoplastic lesions were observed in bisphenol-exposed animals at a higher incidence in comparison with the vehicle control group. Non-neoplastic lesions consisted primarily of squamous metaplasia and hyperplasia (papillary or intraductal) of the mammary gland duct (examples in Figure $6 \mathrm{~A}$ and B), and lobuloalveolar hyperplasia (Rudmann et al. 2012; Figures 17 and 18). Squamous metaplasia was characterized by replacement of the normal differentiated epithelium of the mammary duct with squamous epithelium. Ducts often became cystic and were lined by multiple layers of squamous epithelium and contained intraluminal keratin (Figure 6A). Areas of squamous metaplasia were often focal and were surrounded by low numbers of inflammatory cells that consisted of neutrophils, lymphocytes, plasma cells, and macrophages. Papillary hyperplasia was observed in one animal in the $0.5 \mathrm{mg} / \mathrm{kg}$ BPS groups. Cases of intraductal hyperplasia consisted of an irregular proliferation of the epithelium lining the mammary gland duct (Figure 6B). Lobuloalveolar hyperplasia was characterized by focal to multifocal enlarged lobules consisting of an increased number of relatively normal alveolar epithelial cells. Alveolar epithelial cells were well differentiated, round, and often vacuolated, and they formed one concentric layer around a lumen that typically contained proteinaceous fluid. Ducts were lined by columnar cells and were similar to alveolar cells, with well-differentiated epithelium that formed one concentric layer. Alveoli and ducts were normally distributed, and there was no evidence of compression or cellular atypia. Squamous metaplasia of the mammary gland duct was observed in one animal in the BPAF $5 \mathrm{mg} / \mathrm{kg}$ group. By 14 months of age, there was a significant doserelated increase in diagnoses of non-neoplastic lesion development in the BPAF-exposed groups, and significantly higher incidence in the BPAF $5 \mathrm{mg} / \mathrm{kg}$ group than in the vehicle control group (Table 4). Although the BPS-exposed group had no significant trend, the BPS $0.5 \mathrm{mg} / \mathrm{kg}$ group developed significantly more non-neoplastic lesions than the vehicle controls (Table 4). The BPS $0.5 \mathrm{mg} / \mathrm{kg}$ group had a significantly higher incidence of lobuloalveolar hyperplasia than vehicle controls, whereas the BPAF $5 \mathrm{mg} / \mathrm{kg}$ group demonstrated greater incidence of ductal squamous metaplasia and a significant dose-related trend for the same diagnosis (Table 3). A total of 24 exposed animals were diagnosed with lobuloalveolar hyperplasia of the mammary gland between 8 and 16 months (18 from timed necropsies and 6 from moribund animals; see Table 3 and Table S1).

There were no neoplastic lesions detected in any vehicle control group mammary glands at any time up to 14 months (Table 3), and spontaneous mammary neoplastic lesion development in CD-1 mice is rare, especially in the ages necropsied in this study (Chandra and Frith 1992; Maita et al. 1988; Son and Gopinath 2004). Histopathology identified neoplastic lesions as early as 11 
A

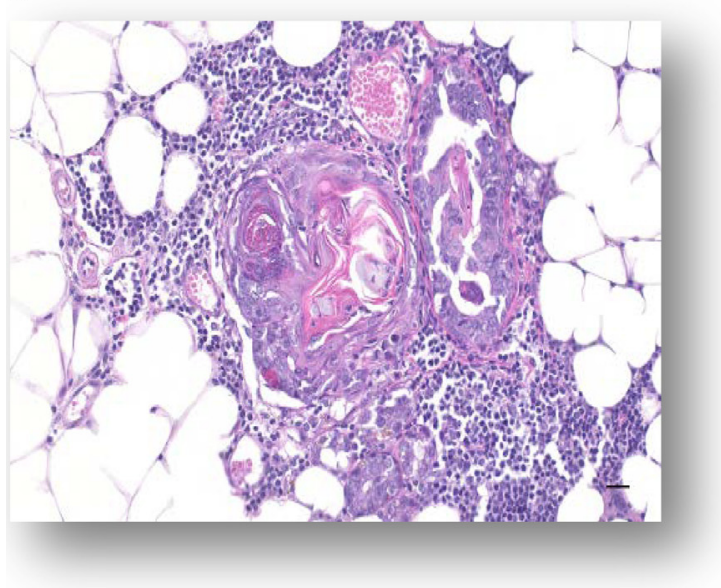

C

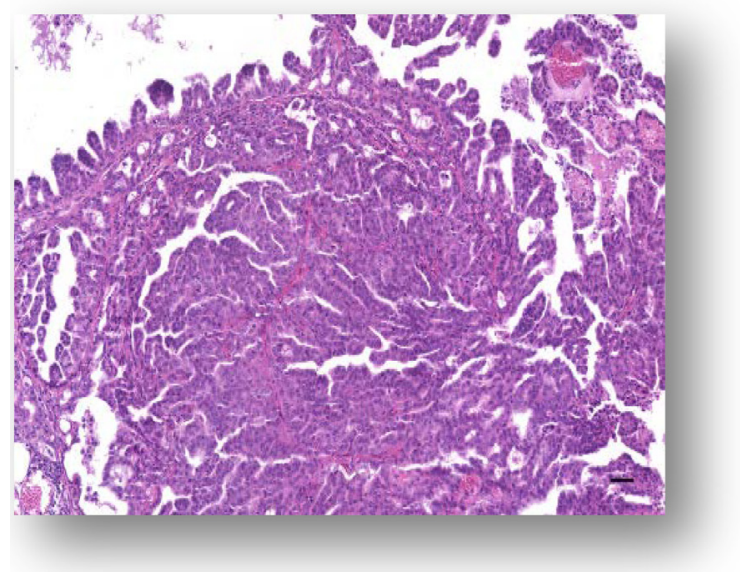

B

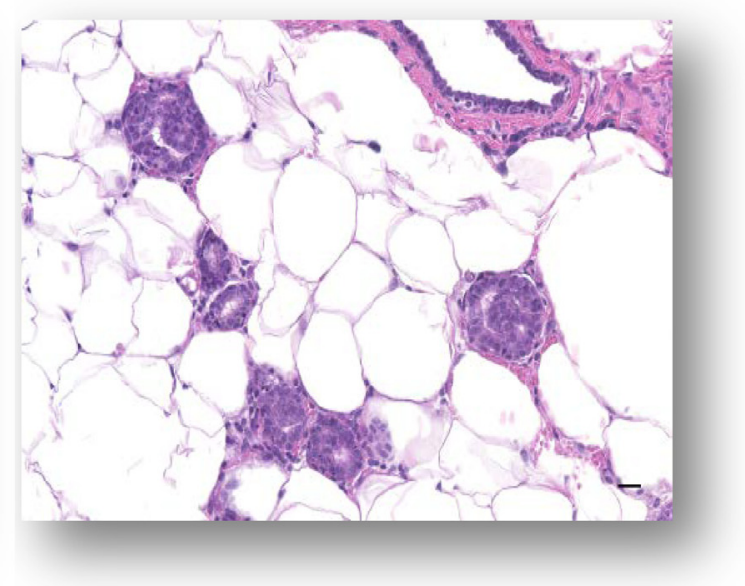

$\mathrm{D}$

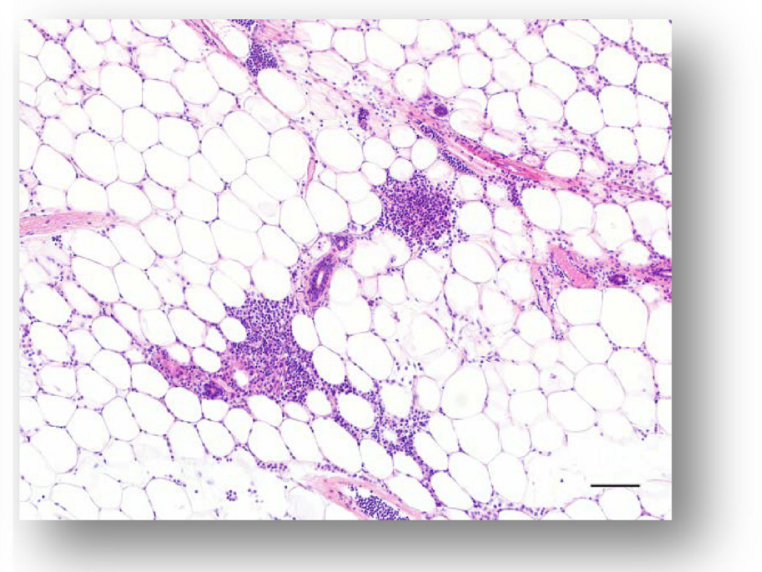

Figure 6. Histological presentation of mammary lesions following early life bisphenol analogue exposure. Representative images illustrate some nonneoplastic lesions: (A) Squamous metaplasia, 20x, bar $=10 \mu \mathrm{m},(B)$ Intraductular hyperplasia 20x, bar $=10 \mu \mathrm{m}$, and $(D)$ Perivascular inflammation, 10x, bar $=20 \mu \mathrm{m}$. Representative image of a neoplastic lesion in $(C)$ Papillary adenocarcinoma, 20x. Bar $=10 \mu \mathrm{m}$.

months (Table S1) in mammary glands of prenatally bisphenolexposed females. Although statistical significance was not achieved for any chemical or dose group, potentially because this study was not powered for tumor formation and because neoplastic lesions were not all diagnosed at the 14 months necropsy, eight different neoplastic lesion types were identified in bisphenol-exposed animals. The multiple mammary neoplastic lesion types diagnosed between 11 and 16 months of age included squamous cell carcinoma $(n=2$; BPAF 5, BPS 0.5), papillary carcinoma $(n=1$; BPS 0.5 ; shown in Figure 6C), adenocarcinoma ( $n=2$; both BPS 5), carcinoma $(n=1$; BPS 0.5$)$, histiocytic sarcoma $(n=1$; BPS 0.5$)$, and benign fibroadenoma $(n=1$; BPS 5$)$, with $88 \%$ of those tumors occurring in the BPS 0.5 or $5 \mathrm{mg} / \mathrm{kg}$ dose groups.

\section{Serum Hormone Analyses}

Serum estradiol, progesterone, testosterone, and dehydroepiandrosterone (DHEA) were measured on PND 20, 35, 56, and at 3, 8, and 14 months in prenatally exposed female offspring (Figure 7 and Figure S2). Prior to VO at PND 20, mean serum estradiol concentrations for animals in all BPAF-exposed and the high- and mid-dose groups of BPS were significantly higher (90-160\%) than vehicle control levels. The estradiol level in animals treated with the highest BPA dose was also higher than that of control animals but failed to reach statistical significance (Figure 7A). Serum progesterone levels were also significantly higher than controls in BPAF $5 \mathrm{mg} / \mathrm{kg}$ and BPS $0.05 \mathrm{mg} / \mathrm{kg}$ groups prior to $\mathrm{VO}$ (Figure 7E). The BPS $0.05 \mathrm{mg} / \mathrm{kg}$ and BPA $50 \mathrm{mg} / \mathrm{kg}$ groups demonstrated elevated DHEA concentrations in comparison with controls (Figure 7M). By PND 28, estradiol, progesterone, and DHEA serum concentrations in all treated groups were similar to vehicle control concentrations, with the exception of testosterone (Figure 7J), which was significantly lower in BPAF $0.05 \mathrm{mg} / \mathrm{kg}$ and higher in BPS $0.05 \mathrm{mg} / \mathrm{kg}$ groups. Interestingly, at PND 35, testosterone concentrations were still lower in BPAF $0.05 \mathrm{mg} / \mathrm{kg}$ (Figure $7 \mathrm{~K}$ ), but not in the same BPS group as at PND 28 Testosterone concentrations at PND 35 in the BPA $5.0 \mathrm{mg} / \mathrm{kg}$, BPAF $0.05 \mathrm{mg} / \mathrm{kg}$, and BPS $0.5 \mathrm{mg} / \mathrm{kg}$ and $5 \mathrm{mg} / \mathrm{kg}$ groups were significantly lower than vehicle control concentrations, some reduced more than 50\%. By PND 56, the only significant differences were higher testosterone and DHEA for the BPA $50 \mathrm{mg} / \mathrm{kg}$ group (Figure $7 \mathrm{~L}$ and $\mathrm{P}$ ).

In contrast to notable differences between treated and vehicle control groups in early life, there were few serum hormone changes in later life (Figure S2). At 3 months, progesterone concentrations tended to be depressed in bisphenol-exposed animals and were significantly lower in BPS $5 \mathrm{mg} / \mathrm{kg}$ groups, in comparison with controls (Figure S2 D). DHEA was also significantly lower, by $27-42 \%$ in at least one dose group, for each compound (Figure S2 J). Estradiol (BPS $0.05 \mathrm{mg} / \mathrm{kg}$ ), testosterone and DHEA (BPS 
Table 4. Evaluation of combined incidences of mammary gland inflammation, neoplasia, non-neoplastic lesions, or lymph node effects at 14 months of age following prenatal exposure to bisphenol A (BPA), bisphenol AF (BPAF), or bisphenol S (BPS).

\begin{tabular}{|c|c|c|c|c|c|c|c|c|c|c|c|c|}
\hline \multirow{3}{*}{$\begin{array}{l}\text { Lesion } \\
\text { Incidence }\end{array}$} & \multirow{2}{*}{$\frac{\text { Vehicle }}{0}$} & \multicolumn{3}{|c|}{ BPA $(\mathrm{mg} / \mathrm{kg})$} & \multirow{2}{*}{$\begin{array}{c}\text { Vehicle } \\
0\end{array}$} & \multicolumn{3}{|c|}{ BPAF (mg/kg) } & \multirow{2}{*}{$\frac{\text { Vehicle }}{0}$} & \multicolumn{3}{|c|}{ BPS (mg/kg) } \\
\hline & & 0.5 & 5 & 50 & & 0.05 & 0.5 & 5 & & 0.05 & 0.5 & 5 \\
\hline & $n=13$ & $n=14$ & $n=11$ & $n=6$ & $n=13$ & $n=14$ & $n=18$ & $n=22$ & $n=13$ & $n=11$ & $n=18$ & $n=13$ \\
\hline $\begin{array}{l}\text { Inflammation, } \\
\text { all types }\end{array}$ & $3(0.156)$ & $5(0.385)$ & $3(0.590)$ & $3(0.257)$ & $3(0.062)$ & $8(0.079)$ & $9(0.126)$ & $14(0.023)^{*}$ & $3(0.159)$ & $4(0.395)$ & $15(0.001)^{* *}$ & $4(0.500)$ \\
\hline Neoplasia & 0 & 0 & 0 & 0 & 0 & 0 & 0 & 0 & $0(0.287)$ & 0 & $2(0.329)_{*}$ & $1(0.500)$ \\
\hline $\begin{array}{l}\text { Non-neoplastic } \\
\text { lesions }\end{array}$ & $0(0.375)$ & $3(0.124)$ & $2(0.199)$ & $1(0.316)$ & $0(<0.001)^{\ddagger}$ & $1(0.518)$ & $3(0.182)$ & $10(0.004)^{* *}$ & $0(0.500)$ & $1(0.458)$ & $7(0.012)^{*}$ & $2(0.240)$ \\
\hline
\end{tabular}

Note: $p$-values for dose-response trends are in parentheses in the Vehicle column; pairwise $p$-values are in the dose columns.

$n=$ indicates number examined.

*Differs from the control group by Fisher's exact test at $p<0.05$; ** $p<0.01$.

${ }^{+}$Significant trend for BPAF by the Cochran-Armitage trend test at $p<0.01$.

$0.5 \mathrm{mg} / \mathrm{kg}$ ) were lower in single-dose groups at 8 months (Figure S2 B, H, K), and no dose-related trends were evident. Serum hormone measurements from 14-month-old animals revealed no significant differences between vehicle control and treated groups.
Mean serum estradiol and progesterone concentrations did not change over this 11-month period, across dose groups. Overall, there was no trend over time or within a chemical or dose group that were detected for any of the serum measurements even

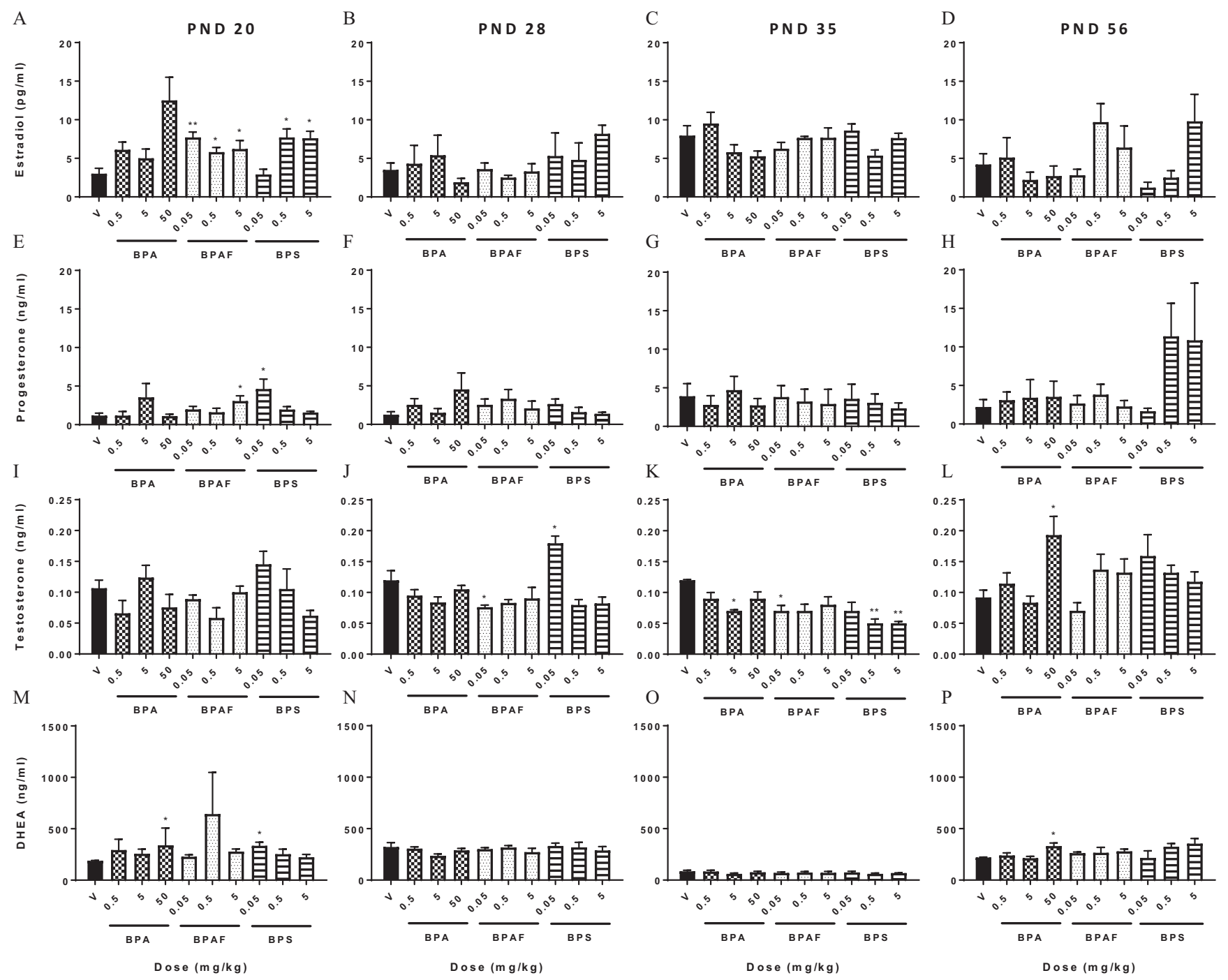

Figure 7. Steroid serum levels from bisphenol A (BPA), bisphenol AF (BPAF), or bisphenol S (BPS)-exposed females during pubertal development. Serum estradiol, progesterone, testosterone, and dehydroepiandrosterone (DHEA) concentrations at postnatal days (PND) (A, $E, I, M)$ PND 20; $(B, F, J, N)$ PND 28; $C$, $G, K, O)$ PND 35; and $(D, H, L, P)$ PND 56, respectively. Mean \pm SEM. ${ }^{*} p<0.05$ is statistically significant in comparison with vehicle control by Dunnett's test. Number of animals per group is noted in Table 1. 

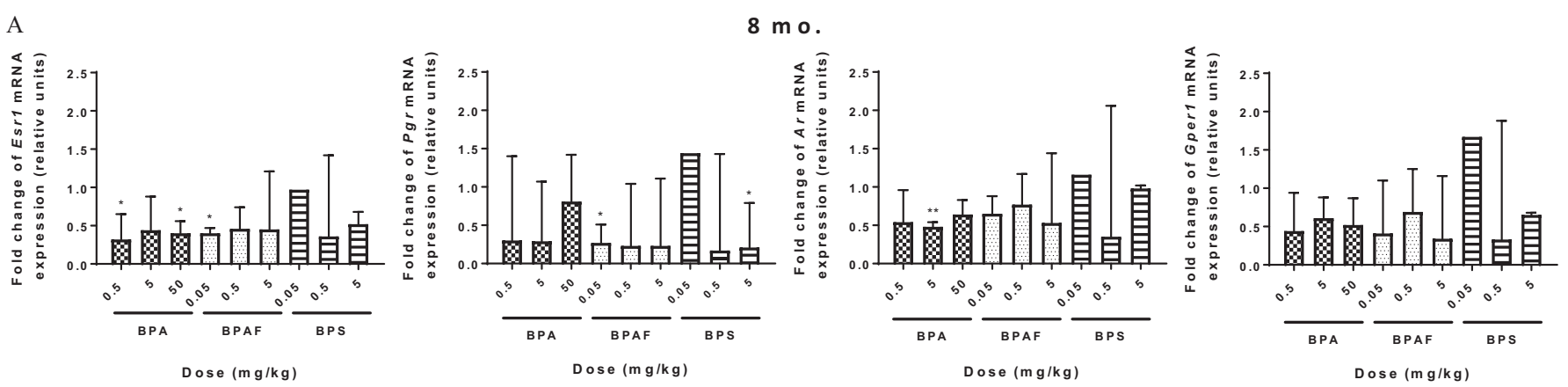

B
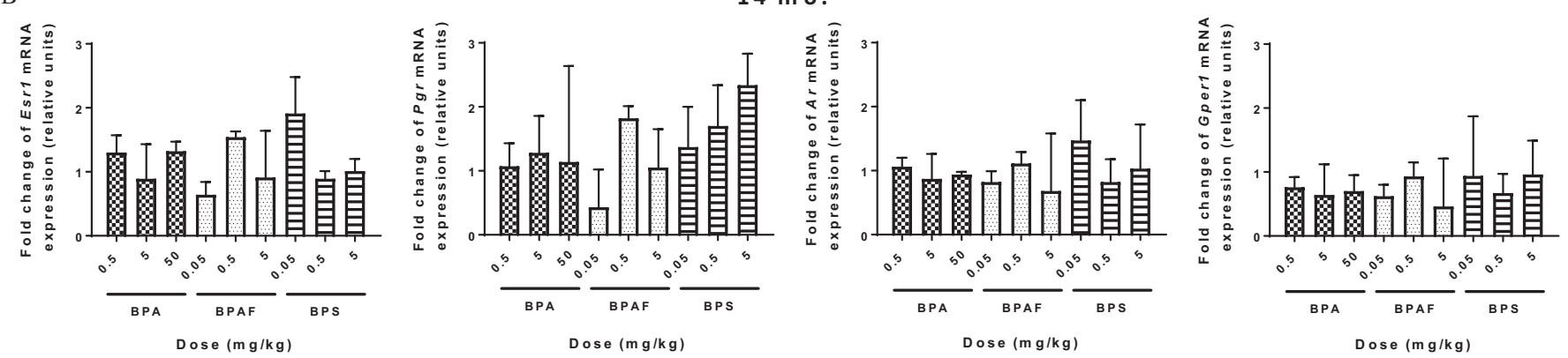

Figure 8. Expression of steroid receptor mRNA in the mammary glands of bisphenol A (BPA), bisphenol AF (BPAF), or bisphenol S (BPS)-exposed females at $(A) 8$ and $(B) 14$ months. Mean \pm SEM. ${ }^{*} p<0.05$ and ${ }^{*} * x<0.01$ is statistically significant compared with vehicle control. $n=3-4$ litters represented, except for 8-month- old BPS $0.05 \mathrm{mg} / \mathrm{kg}$ group $(n=1)$.

though the females were carefully estrous cycle staged prior to necropsy.

\section{Nuclear Receptor Expression in Mammary Tissue}

Because BPA, BPAF, and BPS are all considered to act as endocrine disruptors (Pelch et al. 2017), and specifically act on estrogen receptors, we wanted to test whether an early-life exposure could alter global nuclear receptor expression in the mammary gland and potentially pose as a mechanistic underpinning for phenotypic effects seen later in life. Esrl, Pgr, Ar, and Gperl expression was measured in a subset of mammary gland tissues by RT-PCR at 8 and 14 months (Figure 8), and data are presented relative to the control levels. At the 8-month evaluation (Figure 8A), Esrl expression was significantly decreased in mammary tissue of BPA $0.5 \mathrm{mg} / \mathrm{kg}$ and $50 \mathrm{mg} / \mathrm{kg}$ and BPAF $0.05 \mathrm{mg} / \mathrm{kg}$ groups. Exposure to BPA $50 \mathrm{mg} / \mathrm{kg}$ group resulted in downregulation of $\mathrm{Ar}$, whereas exposure to BPAF $0.05 \mathrm{mg} / \mathrm{kg}$ and BPS $5 \mathrm{mg} / \mathrm{kg}$ reduced $P g r$ expression. No significant differences in steroid receptor expression were observed at 14 months between exposed and vehicle control groups (Figure 8B).

\section{Discussion}

Altered pubertal mammary gland development and increased susceptibility to tumors following early-life exposures to BPA have been illustrated in CD-1 and C57Bl/6 mice (Markey et al. 2001; Muñoz-de-Toro et al. 2005; Wadia et al. 2007). We report not only significantly altered development of mammary tissue, but also doserelated increases in epithelial nonneoplastic lesions and inflammation, and evidence of latent mammary tumor formation, suggesting that structurally related analogues are not suitable BPA replacements and may present more of a risk to the developing breast than BPA presents. Our findings in CD-1 mice suggest that acute prenatal exposure to the BPA analogues, BPAF and BPS, accelerated normal mammary gland development, caused extended retention of TEBs and possible intraductal hyperplasia, and increased the incidence of persistent proliferative effects in the mammary gland in exposed siblings. Significantly higher incidence of inflammation was detected in exposed groups exhibiting nonneoplastic lesions (lobuloalveolar hyperplasia, intraductal hyperplasia, ductal squamous metaplasia) and spontaneous adenocarcinomas. The BPS $5 \mathrm{mg} / \mathrm{kg}$ group adenocarcinomas appeared at $<12$ months of age, and $88 \%$ of all neoplasia formed at the two highest BPS doses tested (2 occurred in one litter).

Importantly, the mammary gland was a sensitive target for BPA, $\mathrm{BPAF}$, and BPS, as exposure caused accelerated pubertal mammary development without altering other pubertal indicators (VO timing, age at first estrus, or estrous cyclicity) or BW. This finding is not the first report of the mammary gland being a sensitive pubertal endpoint; BPA (Murray et al. 2007; Muñoz-de-Toro et al. 2005; Jenkins et al. 2009), PFOA (Tucker et al. 2015), atrazine, and other structurally varied chemicals (summarized in Rudel et al. 2011) have specifically affected pubertal mammary development at doses that were without effect on other pubertal indices in rat and mouse models. The importance of identifying environmental modifiers that significantly alter mammary development without affecting other aspects of puberty is paramount, as girls worldwide are developing breasts months to years earlier than those a generation before them did, without changes to their menstrual timing (Biro et al. 2013 and Aksglaede et al. 2009).

Compromised mammary gland development before birth may account for the many alterations and manifestations that arise in the gland later in life, especially following endocrine-disruptor exposures. This study showed that by PND 20 mammary glands from treated groups had an increased number of TEBs, as well as increased branching density and TEBs per glandular area; these characteristics occurred in a dose-dependent manner, persisted into young adulthood (PND 56; 8 wk), and were concomitant with a prepubertal rise in serum estradiol. An increase in TEB counts and TEB and ductal area within one month of birth following low-level BPA exposure has been previously observed in CD-1 and C57Bl/6 mice (Markey et al. 2005; Muñoz-de-Toro et al. 2005; Wadia et al. 2007), but here, TEBs were still present 
in $41-75 \%$ of mammary glands from nearly every chemically exposed group at 3 months. Retention of the TEB into adulthood was unexpected, as rapidly proliferating epithelium typically undergoes precocious differentiation of its duct ends. Their presence and differentiation are typically carefully orchestrated through a series of paracrine, endocrine, and autocrine events; however, the shift of these events may alter the timing and longevity of their presence. Rapidly dividing cells of the TEB are sensitive to the effects of carcinogens and endogenous hormones critical for cell proliferation (Russo et al. 1983), and a recent study evaluating mammary response to fracking chemicals in $\mathrm{C} 57 \mathrm{Bl} / 6$ mice has also reported TEB-like structures in whole mounts that were diagnosed as intraductal hyperplasia after sectioning (Sapouckey et al. 2018). Future studies should employ sectioning of whole mounted mouse mammary tissue, or at least potential lesions and their surrounding tissue, to further identify EDCs adversely affecting mammary health. The presence of TEBs over multiple estrous cycles introduces intermittent exposures to endogenous hormones, and our data suggest that such intermittent exposures may have increased the risk for later life lesion development.

Studies in Sprague-Dawley rats have demonstrated the effects of early BPA exposure on the formation of preneoplastic and neoplastic mammary gland lesions (Betancourt et al. 2010; Jenkins et al. 2009). Fetal exposure to low doses of BPA via osmotic pumps produced ductal hyperplasia and carcinoma, in situ in Wistar-Furth rats at PND 50 and 95, that were confirmed to be actively proliferating (Murray et al. 2007). Similarly, Sprague-Dawley rats developed mammary adenocarcinomas following "gestational only" and a "combination of gestational and lactational" exposure to BPA (Acevedo et al. 2013). The few studies shown to induce mammary tumors following BPA exposure in a rat model have involved a mammary carcinogen (e.g., DMBA; Betancourt et al. 2010, Jenkins et al., 2009). Also, Weber et al. (2011) have shown that, following prenatal exposure to 25 or $250 \mu \mathrm{g} / \mathrm{kg}$ BPA, FVB/N female mouse offspring given DMBA had a significantly higher predisposition for mammary tumors. In our study, no animals from the BPA-dosed dams developed a tumor of any type (although BPAF and BPSexposed mice did). We presume that the inability to obtain the same results in this study as the results of previous BPA-specific studies may be attributed to a difference in internal dose, use of a strain of mouse that is not prone to mammary tumors, or more important, the lack of a "second hit" from a chemical carcinogen.

Insufficient evidence in humans exists to delineate a role for BPA in adversely changing the breast environment, and a limited number of studies have adequately evaluated associations between BPA exposure and breast cancer risk in women (Sprague et al. 2013; Trabert et al. 2014; Yang et al. 2009). Canadian women working in the following occupations had elevated breast cancer risk: occupational and industrial manufacturers of automotive plastics, food canning, agriculture, and service in bar or gambling establishments, with the highest risk for premenopausal women working in food canning [odds ratio $(\mathrm{OR})=5.70 ; 95 \%$ confidence interval (CI): 1.03, 31.5] and automotive plastics $(\mathrm{OR}=4.76 ; 95 \%$ CI: $1.58,14.4$ ) (Brophy et al. 2012). These women were likely exposed to a mixture of bisphenol analogues (although they were not measured), among other industrial chemicals. At best, these studies provide a relationship between adult exposure to plasticizers and the risk for breast cancer but do not begin to address the several established and emerging breast cancer risk factors identified in premenopausal women, which include increased breast density, lifestyle, menstrual history, and exposure to chemicals during sensitive life stages (e.g., DES, PAHs, DDT, and BPA) (Gammon et al. 2002; Gammon et al. 2004; Troisi et al. 2007; Cohn et al. 2015).

Increasing evidence suggests that the role of the immune system is critical in the manifestation of breast cancer (Brady et al. 2016; Condeelis and Pollard 2006; Coussens and Pollard 2011). We noted a higher incidence of inflammatory infiltrates composed primarily of lymphocytes, plasma cells, and macrophages in the mammary gland of every bisphenol-exposed group, with the suggestion of a dose-response trend $(p=0.06)$ in the BPAF group, and significantly more inflammatory infiltrates in the BPAF $5 \mathrm{mg} / \mathrm{kg}$ and BPS $0.5 \mathrm{mg} / \mathrm{kg}$ - exposed groups than in vehicle controls. Macrophages play an essential role in the mammary microenvironment during normal development and breast cancer progression. A recent study in strains of mice with a high propensity to form mammary tumors describes increased macrophage recruitment to mammary tissue prior to tumor formation following high-fat diet treatment. Modified immune function was theorized to drive increased tumor burden in treated mice (Zhu et al. 2017). With respect to our data, the increased incidence of inflammation throughout mammary development may have been influenced by early changes in immunomodulatory responses. Further studies, focused on early-life mammary-specific chemokine/cytokine changes, will be necessary to evaluate this mechanism. The fact that over $90 \%$ of the inflammation diagnoses occurred in doses $\leq 5 \mathrm{mg}$ bisphenol $/ \mathrm{kg}$ in our study may suggest that inflammatory responses are sensitive endpoints for BPA and the other analogues. It should also be noted that macrophages and other leukocytic infiltrates are necessary during pubertal and adult human breast development for the formation of the first TEBs; macrophages regulate and maintain an immunostimulatory presence throughout the estrous cycle (Gouon-Evans et al. 2002; Howard and Gusterson 2000). It is not clear if the noted inflammatory patches in our study are an acute immune response to a perceived "injury," or if this finding is part of a tissueremodeling event that prepares a niche for tumor development. A potential shift in important immune responses may suggest the reason for the extended presence of the TEBs at 3 months and requires further investigation.

Lobuloalveolar hyperplasia was also observed in every bisphenol treated group by 14 months, with the exception of BPAF and BPS $0.05 \mathrm{mg} / \mathrm{kg}$ groups. In rodents, lobuloalveolar hyperplasia often resembles the mammary gland from pregnant female rodents or pseudopregnancy and, in some but not all cases, may lead to an advanced hyperplastic state of the mammary gland. Vandenberg et al. (2008) observed increased alveolar buds and lobuloalveolar units as early as 3 months in CD- 1 females following a perinatal exposure to BPA $(0.25,2.5$, or $25 \mu \mathrm{g} / \mathrm{kg})$. By 9 months, intraductal hyperplastic lesions or "beaded ducts" were prevalent in multiple animals, similar to ductal bridging reported following perinatal genistein administration in CD-1 mice (Padilla-Banks et al. 2006). BPA also produced lobuloalveolar hyperplasia at PND 90 and 140 in Sprague-Dawley rats exposed through a gestational $(250 \mu \mathrm{g} / \mathrm{kg})$ or gestational/lactational $(0.25-$ and $25-\mu \mathrm{g} / \mathrm{kg}$ ) exposure (Acevedo et al. 2013). Mammary glands from Crl:CD BR rat offspring exposed to estradiol from gestation to PND 90 also developed these structures(Biegel et al. 1998). Lobuloalveolar hyperplasia is considered a nonneoplastic lesion and to date no associations have been made between these structures and tumor formation, but they frequently develop following exposure to hormones and endocrine disruptors. Studies are needed to identify which preneoplastic lesions contain cells capable of producing tumors in transplant studies.

Although the sequence of events that leads from prenatal chemical exposure during organogenesis to altered morphogenesis and cancer is not understood, a weight of evidence is emerging that exposure to these chemicals during sensitive developmental periods produces persistent changes in growth, function, and cancer in that tissue over the lifespan. BPA is considered an estrogenic compound, and therefore we were interested in determining if there would be changes in serum hormone concentrations well after 
prenatal exposure to BPA, BPAF, or BPS. Both BPAF and BPS have been shown to be agonists for ER $\alpha$, (Pelch et al. 2017) and produce proliferative effects in MCF-7 cells (Hashimoto et al. 2001; Matsushima et al. 2010; Perez et al. 1998; Rivas et al. 2002). In our study, serum estradiol, progesterone, and DHEA concentrations were increased very early during puberty (PND 20), complementing or potentially stimulating precocious mammary gland morphological changes. At PND 28 and 35, only testosterone concentrations were altered and were mostly reductions; by PND 56, increases in estradiol and DHEA were observed in the BPA $50 \mathrm{mg} / \mathrm{kg}$ group. By 3 months, no dose-related trends were noted; however, all significant hormone changes were noted as reductions. DHEA, in particular, was reduced in several bisphenol groups at 3 months and BPS $0.5 \mathrm{mg} / \mathrm{kg}$ at 8 months. In humans and other primates, the adrenal glands serve as a main contributor to DHEA secretion, which can then be converted to both estrogens and androgens in target tissues, including the ovaries (Labrie 2006). DHEA and other androgens have been implicated as having inhibitory effects against mammary proliferation, and because circulating concentrations of DHEA tend to decrease in women between the ages of 20 and 50, there is reason to believe that the decline in DHEA may contribute to incidence or progression of breast cancer (Birrell et al. 1998; Buchanan et al. 2005; Labrie et al. 2003).

The mammary gland is composed of various tissue and cell types that are governed by endocrine, autocrine, and paracrine signals. Therefore, there is probably no definitive mechanism of action for BPA and mammary tumor formation, and the same may be true for BPAF and BPS. Our data suggests a link between bisphenol exposure and the development of lobuloalveolar hyperplasia formation in the mammary gland, and we theorize that prolactin is possibly playing a role. Exposure to estrogenic xenobiotics have caused hyperprolactinemia and lobuloalveolar hyperplasia in female rats (reviewed in Lucas et al. 2007), but it is not clear if this is a strain- or species-related phenotype. This potential mechanism warrants further investigation, but study samples were not collected in a way that allowed for proper evaluation of prolactin-related responses, so further studies are needed.

$\mathrm{ER} \alpha$ is expressed in fetal stromal cells but not in epithelium (Speroni et al. 2017). This finding suggests that because estrogenic pathways are less influential in the epithelium during fetal mammary gland development, the stroma plays a major role in the signaling changes seen within the epithelium. It is quite possible that these early-life mechanistic changes are driving the altered phenotypes observed at puberty and in later life. Mammary gland gene expression analysis of Esrl, Pgr, Ar, and Gperl as well as serum hormone concentrations showed very few changes at 8 months and no changes at 14 months that would point to a direct classical estrogen-mediated mode of action. In a previous study at PND 50, BPA treated Sprague-Dawley rats $(250 \mu \mathrm{g} / \mathrm{kg})$ had no change in protein expression of $\mathrm{ER} \alpha$; however, $\mathrm{PR}-\mathrm{A}$, which is vital for ductal elongation, and the downstream coregulators SRC-1, SRC-2, and SRC-3, were all significantly increased (Jenkins et al. 2009). Rosenmai et al. (2014) also showed that although BPS increased estrogenic activity in vitro, it was the least potent and showed only a decreasing trend in activity for the androgen receptor assay. Therefore, it will be necessary to explore other additional pathways and mechanisms, including pubertal mammary stem and progenitor cell changes and the epigenome for these persistent effects of bisphenols.

When this research began, the only human bisphenol data that existed was on BPA. One report published recently measured serum BPS in cashiers pre- and postshift (Thayer et al. 2016), but besides that report, there are limited quality reports of BPAF and BPS serum measurements from the general human population. Therefore, estimating an administration dose for human relevance relied on using BPA data, and therefore our lowest BPAF and BPS doses are at the calculated EPA reference dose for daily BPA exposures: $50 \mu \mathrm{g} / \mathrm{kg} / \mathrm{BW}(0.05 \mathrm{mg} / \mathrm{kg} / \mathrm{BW})$ (U.S. EPA 1988). Regardless, strength of this work is that the affected offspring were exposed to low, potentially human-relevant concentrations of these bisphenol metabolites (not parent chemical) through placental transfer. Our data indicate that whatever modification was made to the bisphenols in the pregnant mother, they actively affected the mammary gland of the developing fetus. Current research is focused on determining the disposition and speciation of the effective bisphenol components.

This study has limitations: It was not powered for detection of tumors in late life, thus dose group sizes were not consistent over time, and our findings regarding tumor development are preliminary. However, an adenocarcinoma was identified as early as 11 months in the BPS high-dose group, with a second finding a month later in the same dose group. The BPS $0.5 \mathrm{mg} / \mathrm{kg}$ group presented with a multitude of tumors likely arising from one or a combination of the many cell types that compose the mammary gland. The CD-1 strain is an outbred strain that has been shown to develop spontaneous mammary tumors in both control male and females at 18 months or $2 \mathrm{y}$; however, many of these lesions were not identified until the animals were 2 years old, with the exception of one analysis where a single female developed a mammary adenocarcinoma at 41-45 wk (Chandra and Frith 1992; Giknis and Clifford 2013; Maita et al. 1988; Son and Gopinath 2004). Although it is possible that the 2-year-old animals developed tumors that went undetected, the fact that none of our vehicle controls at 3, 8, or 14 months developed a neoplasm, or nonneoplastic lesion of any sort, may suggest that the diagnosed tumors in our study may truly be because of early-life exposure to the bisphenols. Future studies addressing the propensity for tumor development following prenatal bisphenol analogues exposure should be more well powered than ours and should investigate early biomarkers of late life disease that were evident in this study. Another minor limitation is that in the design of this study, insufficient quantities of tissue and serum were collected for early-life gene and hormone evaluations. Since this study was conducted, another short-term study with identical treatment conditions has been conducted so that mammary tissue could be analyzed for early-life gene changes on a genome-wide level. Those data are undergoing analyses. The validity of mass spectrometry methods for measuring several ( $>6$ or 8 ) hormones in a small volume of mouse blood is also being investigated to improve the ability to associate hormone changes with phenotypic outcomes.

\section{Conclusion}

Our findings suggest that exposure to BPAF and BPS by consumers such as women of child-bearing age or infants and children should be restricted. The fetal mammary gland is a sensitive target organ for these chemicals. BPAF and BPS prenatally exposed female mice developed proliferative epithelial lesions by midlife, concomitant with a significant inflammatory response that may predispose them to tumor formation later in life. In fact, animals in the high-dose BPS group developed adenocarcinomas prior to one year of life and those diagnoses triggered a necropsy at 14 months of age in the remaining animals. Most neoplasia incidents in this study (7/8) occurred in the BPS-exposed animals. The extended presence of TEBs into adulthood (confirmed by histopathology), the significant prepubertal spikes in serum estradiol, and the altered immune responses (e.g., increased perivascular inflammation) may have been important modifiers of the persistent adverse effects observed later in life. To our knowledge, this study is the first report of BPAF- and BPS-induced adverse developmental effects in the mammary gland, and these findings 
warrant further studies to determine relevance of these findings for human breast cancer susceptibility.

\section{Acknowledgments}

The authors acknowledge J. Foley, NIEHS, for her technical expertise and assistance with the whole mount to histopathology sectioning project. Appreciation is extended to Dr. V. Chappell, Kelly contractor, for assistance in figure production and to Dr. Vicki Sutherland, NTP, for helpful discussions in study design.

This work was funded by the Division of the National Toxicology Program, NIEHS (Z01ES102785; SEF). D.K.T. was supported by a NIEHS Individual Research Training Award.

\section{References}

Acevedo N, Davis B, Schaeberle CM, Sonnenschein C, Soto AM. 2013. Perinatally administered bisphenol $A$ as a potential mammary gland carcinogen in rats. Environ Health Perspect 121(9):1040-1046, PMID: 23876597, https://doi.org/10. 1289/ehp.1306734

Aksglaede L, Sørensen K, Petersen JH, Skakkebaek NE, Juul A. 2009. Recent decline in age at breast development: the Copenhagen Puberty Study. Pediatrics 123(5): e932-e939, PMID: 19403485, https://doi.org/10.1542/peds.2008-2491.

Betancourt AM, Eltoum IA, Desmond RA, Russo J, Lamartiniere CA. 2010. In utero exposure to bisphenol A shifts the window of susceptibility for mammary carcinogenesis in the rat. Environ Health Perspect 118(11):1614-1619, PMID: 20675265, https://doi.org/10.1289/ehp.1002148.

Biegel LB, Flaws JA, Hirshfield AN, O'Connor JC, Elliott GS, Ladics GS. 1998. 90day feeding and one-generation reproduction study in CRL:CD BR rats with 17 beta-estradiol. Toxicological sciences 44(2):116-142, PMID: 9742652, https://doi.org/10.1006/toxs.1998.2468.

Biro FM, Greenspan LC, Galvez MP, Pinney SM, Teitelbaum S, Windham GC, et al. 2013. Onset of breast development in a longitudinal cohort. Pediatrics 132(6):10191027, PMID: 24190685, https://doi.org/10.1542/peds.2012-3773.

Birrell SN, Hall RE, Tilley WD. 1998. Role of the androgen receptor in human breast cancer. J Mammary Gland Biol Neoplasia 3(1):95-103, PMID: 10819508.

Brady NJ, Chuntova P, Schwertfeger KL. 2016. Macrophages: regulators of the inflammatory microenvironment during mammary gland development and breast cancer. Mediators Inflamm 2016:4549676, PMID: 26884646, https://doi.org/10.1155/2016/ 4549676.

Brophy JT, Keith MM, Watterson A, Park R, Gilbertson M, Maticka-Tyndale E, et al. 2012. Breast cancer risk in relation to occupations with exposure to carcinogens and endocrine disruptors: a Canadian case-control study. Environ Health 11:87, PMID: 23164221, https://doi.org/10.1186/1476-069X-11-87.

Buchanan G, Birrell SN, Peters AA, Bianco-Miotto T, Ramsay K, Cops EJ, et al. 2005. Decreased androgen receptor levels and receptor function in breast cancer contribute to the failure of response to medroxyprogesterone acetate. Cancer research 65:8487-8496, PMID: 16166329, https://doi.org/10.1158/00085472.CAN-04-3077.

Calafat AM, Ye X, Wong LY, Reidy JA, Needham LL. 2008. Exposure of the U.S. population to bisphenol A and 4-tertiary-octylphenol: 2003-2004. Environmental health perspectives 116:39-44, PMID: 18197297, https://doi.org/10.1289/ehp.10753.

CDC (Centers for Disease Control and Prevention). 2017. Fourth National Report on Human Exposure to Environmental Chemicals. https://www.cdc.gov/ exposurereport/pdf/FourthReport_UpdatedTables_Volume1_Mar2018.pdf. [accessed 23 March 2018].

Chandra M, Frith CH. 1992. Spontaneous neoplasms in aged CD-1 mice. Toxicol Lett 61:67-74, PMID: 1609440.

Cohn BA, La Merrill M, Krigbaum NY, Yeh G, Park JS, Zimmermann L, et al. 2015. DDT exposure in utero and breast cancer. J Clin Endocrinol Metab 100(8):2865-2872, PMID: 26079774, https://doi.org/10.1210/jc.2015-1841.

Condeelis J, Pollard JW. 2006. Macrophages: obligate partners for tumor cell migration, invasion, and metastasis. Cell 124(2):263-266, PMID: 16439202, https://doi.org/ 10.1016/j.cell.2006.01.007

Coussens LM, Pollard JW. 2011. Leukocytes in mammary development and cancer. Cold Spring Harb Perspect Biol 3(3):a003285, https://doi.org/10.1101/cshperspect. a003285.

Davis BJ, Fenton SE. 2013. The mammary gland. In: Haschek and Rousseaux's Handbook of Toxicologic Pathology. Haschek W., Rousseaux, C., and Wallig M. (eds.):, 3rd ed. Cambridge, MA: Academic Press, 2665-2694.

Dessi-Fulgheri F, Porrini S, Farabollini F. 2002. Effects of perinatal exposure to bisphenol $A$ on play behavior of female and male juvenile rats. Environ Health Perspect 110 Suppl 3:403-407, PMID: 12060836, https://doi.org/10.1289/ehp.02110s3403.
Doerge DR, Vanlandingham M, Twaddle NC, Delclos KB. 2010. Lactational transfer of bisphenol A in Sprague-Dawley rats. Toxicol Lett 199(3):372-376, PMID: 20933065, https://doi.org/10.1016/j.toxlet.2010.09.022.

Durando M, Kass L, Piva J, Sonnenschein C, Soto AM, Luque EH, et al. 2007. Prenatal bisphenol A exposure induces preneoplastic lesions in the mammary gland in Wistar rats. Environ Health Perspect 115(1):80-86, PMID: 17366824.

Enoch RR, Stanko JP, Greiner SN, Youngblood GL, Rayner JL, Fenton SE. 2007. Mammary gland development as a sensitive end point after acute prenatal exposure to an atrazine metabolite mixture in female Long-Evans rats. Environ Health Perspect 115(4):541-547, PMID: 17450222, https://doi.org/10.1289/ehp. 9612.

Fernández MF, Rivas A, Olea-Serrano F, Cerrillo I, Molina-Molina JM, Araque P, et al. 2004. Assessment of total effective xenoestrogen burden in adipose tissue and identification of chemicals responsible for the combined estrogenic effect. Anal Bioanal Chem 379(1):163-170, PMID: 15024544, https://doi.org/10. 1007/s00216-004-2558-5.

Gammon MD, Santella RM, Neugut Al, Eng SM, Teitelbaum SL, Paykin A, et al. 2002. Environmental toxins and breast cancer on Long Island. I. Polycyclic aromatic hydrocarbon DNA adducts. Cancer Epidem Biomar 11:677-685, PMID: 12163319.

Gammon MD, Eng SM, Teitelbaum SL, Britton JA, Kabat GC, Hatch M, et al. 2004. Environmental tobacco smoke and breast cancer incidence. Environ Res 96(2):176-185, PMID: 15325878, https://doi.org/10.1016/j.envres.2003.08.009.

Gerona RR, Pan J, Zota AR, Schwartz JM, Friesen M, Taylor JA, et al. 2016. Direct measurement of Bisphenol A (BPA), BPA glucuronide and BPA sulfate in a diverse and low-income population of pregnant women reveals high exposure, with potential implications for previous exposure estimates: a cross-sectional study. Environ Health 12:1-14, PMID: 27071747, https://doi.org/10.1186/s12940016-0131-2.

Giknis MLA, Clifford CB. 2013. Compilation of spontaneous neoplastic lesions and survival in CRL:CD (SD) rats from control groups. https://www.criver.com/ resources [accessed 5 October 2016].

Goldman JM, Murr AS, Cooper RL. 2007. The rodent estrous cycle: characterization of vaginal cytology and its utility in toxicological studies. Birth Defects Res B Dev Reprod Toxicol 80(2):84-97, PMID: 17342777, https://doi.org/10.1002/bdrb. 20106.

Gore AC, Chappell VA, Fenton SE, Flaws JA, Nadal A, Prins GS, et al. 2015. EDC-2: The Endocrine Society's Second Scientific Statement on Endocrine-Disrupting Chemicals. Endocr Rev 36(6):E1-E150, PMID: 26544531, https://doi.org/10.1210/ er.2015-1010.

Gouon-Evans V, Lin EY, Pollard JW. 2002. Requirement of macrophages and eosinophils and their cytokines/chemokines for mammary gland development Breast Cancer Res 4(4):155-164, PMID: 12100741.

Hashimoto Y, Moriguchi Y, Oshima H, Kawaguchi M, Miyazaki K, Nakamura M. 2001. Measurement of estrogenic activity of chemicals for the development of new dental polymers. Toxicol In Vitro 15(4-5):421-425, PMID: 11566573.

Hilakivi-Clarke L, Cho E, Raygada M, Kenney N. 1997. Alterations in mammary gland development following neonatal exposure to estradiol, transforming growth factor alpha, and estrogen receptor antagonist ICI 182,780. J Cell Physiol 170(3):279-289, PMID: 9066785, https://doi.org/10.1002/(SICI)1097-4652(199703) 170:3\&lt;279::AID-JCP9\&gt;3.0.C0;2-L.

Hines EP, White SS, Stanko JP, Gibbs-Flournoy EA, Lau C, Fenton SE. 2009. Phenotypic dichotomy following developmental exposure to perfluorooctanoic acid (PFOA) in female CD-1 mice: low doses induce elevated serum leptin and insulin, and overweight in mid-life. Mol Cell Endocrinol 304(1-2):97-105, PMID: 19433254, https://doi.org/10.1016/j.mce.2009.02.021.

Howard BA, Gusterson BA. 2000. Human breast development. J Mammary Gland Biol Neoplasia 5(2):119-137, PMID: 11149569.

Jenkins S, Raghuraman N, Eltoum I, Carpenter M, Russo J, Lamartiniere CA. 2009 Oral exposure to bisphenol $A$ increases dimethylbenzanthracene-induced mammary cancer in rats. Environ Health Perspect 117(6):910-915, PMID: 19590682, https://doi.org/10.1289/ehp.11751.

Kitamura S, Suzuki T, Sanoh S, Kohta R, Jinno N, Sugihara K, et al. 2005. Comparative study of the endocrine-disrupting activity of bisphenol $A$ and 19 related compounds. Toxicol Sci 84(2):249-259, PMID: 15635150, https://doi.org/10.1093/toxsci/ kfi074.

Kolla S, Morcos M, Martin B, Vandenberg LN. 2018. Low dose bisphenol S or ethyinyl estradiol exposures during the perinatal period alter female mouse mammary gland development. Reprod. Toxicol 78:50-59, PMID: 29526645, https://doi.org/10.1016/j.reprotox.2018.03.003.

Labrie F, Luu-The V, Labrie C, Bélanger A, Simard J, Lin SX, et al. 2003. Endocrine and intracrine sources of androgens in women: inhibition of breast cancer and other roles of androgens and their precursor dehydroepiandrosterone. Endocr Rev 24(2):152-182, PMID: 12700178, https://doi.org/10.1210/er.2001-0031. 
Labrie F. 2006. Dehydroepiandrosterone, androgens and the mammary gland. Gynecol Endocrinol 22(3):118-130, PMID: 16835073, https://doi.org/10.1080/ 09513590600624440

LaPlante CD, Catanese MC, Bansal R, Vandenberg LN. 2017. Bisphenol S alters the lactating mammary gland and nursing behavior in mice exposed during pregnancy and lactation. Endorinology 1:158(10):3448-3461, PMID: 28977596, https://doi.org/10.1210/en.2017-00437.

Liao C, Liu F, Alomirah H, Loi VD, Mohd MA, Moon HB, 2012a. Bisphenol S in urine from the United States and seven Asian countries: occurrence and human exposures. Environ Sci Technol 46:6860-6866.

Liao C, Kannan K. 2013. Concentrations and profiles of bisphenol A and other bisphenol analogues in foodstuffs from the United States and their implication for human exposure. J Agric Food Chem 61(19):4655-4662, PMID: 23614805, https://doi.org/10.1021/jf400445n.

Liao CY, Liu F, Guo Y, Moon HB, Nakata H, Wu Q, et al. 2012b. Occurrence of eight bisphenol analogues in indoor dust from the United States and several Asian countries: implications for human exposure. Environ Sci Technol 46(16):91389145, PMID: 22784190, https://doi.org/10.1021/es302004w.

Liao CY, Liu F, Kannan K. 2012c. Bisphenol S, a new bisphenol analogue, in paper products and currency bills and its association with bisphenol A residues. Environ Sci Technol 46(12):6515-6522, PMID: 22591511, https://doi.org/10.1021/es300876n.

Lucas JN, Rudmann DG, Credille KM, Irizarry AR, Peter A, Snyder PW. 2007. The rat mammary gland: morphologic changes as an indicator of systemic hormonal perturbations induced by xenobiotics. Toxicol Pathol 35(2):199-207, PMID: 17366314, https://doi.org/10.1080/01926230601156260.

Macon MB, Villanueva LR, Tatum-Gibbs K, Zehr RD, Strynar MJ, Stanko JP, et al. 2011. Prenatal perfluorooctanoic acid exposure in CD-1 mice: low-dose developmental effects and internal dosimetry. Toxicol Sci 122(1):134-145, PMID: 21482639, https://doi.org/10.1093/toxsci/kfr076.

Maita K, Hirano M, Harada T, Mitsumori K, Yoshida A, Takahashi K, et al. 1988. Mortality, major cause of moribundity, and spontaneous tumors in CD-1 mice. Toxicol Pathol 16(3):340-349, PMID: 3194656, https://doi.org/10.1177/ 019262338801600305.

Markey CM, Luque EH, Munoz De Toro M, Sonnenschein C, Soto AM. 2001. In utero exposure to bisphenol $\mathrm{A}$ alters the development and tissue organization of the mouse mammary gland. Biol Reprod 65(4):1215-1223, PMID: 11566746.

Markey CM, Wadia PR, Rubin BS, Sonnenschein C, Soto AM. 2005. Long-term effects of fetal exposure to low doses of the xenoestrogen bisphenol-A in the female mouse genital tract. Biol Reprod 72(6):1344-1351, PMID: 15689538, https://doi.org/10.1095/biolreprod.104.036301.

Matsushima A, Liu X, Okada H, Shimohigashi M, Shimohigashi Y. 2010. Bisphenol $\mathrm{AF}$ is a full agonist for the estrogen receptor ER-alpha but a highly specific antagonist for ER-beta. Environ Health Perspect 118(9):1267-1272, PMID: 20427257, https://doi.org/10.1289/ehp.0901819.

Mendonca K, Hauser R, Calafat AM, Arbuckle TE, Duty SM. 2014. Bisphenol A concentrations in maternal breast milk and infant urine. Int Arch Occup Environ Health 87(1):13-20, PMID: 23212895, https://doi.org/10.1007/s00420-012-0834-9.

Moral R, Wang R, Russo IH, Lamartiniere CA, Pereira J, Russo J. 2008. Effect of prenatal exposure to the endocrine disruptor bisphenol A on mammary gland morphology and gene expression signature. J Endocrinol 196(1):101-112, PMID: 18180321, https://doi.org/10.1677/J0E-07-0056.

Muñoz-de-Toro M, Markey CM, Wadia PR, Luque EH, Rubin BS, Sonnenschein C, et al. 2005. Perinatal exposure to bisphenol-A alters peripubertal mammary gland development in mice. Endocrinology 146(9):4138-4147, PMID: 15919749, https://doi.org/10.1210/en.2005-0340.

Murray TJ, Maffini MV, Ucci AA, Sonnenschein C, Soto AM. 2007. Induction of mammary gland ductal hyperplasias and carcinoma in situ following fetal bisphenol A exposure. Reprod Toxicol 23(3):383-390, PMID: 17123778, https://doi.org/10.1016/j. reprotox.2006.10.002.

NIOSH (National Institute for Occupational Safety and Health). 1990. National Occupational Exposure Survey (1981-1983). Estimated numbers of employees potentially exposed to specific agents by occupation within 2-digit standard industrial classification (SIC). https://www.cdc.gov/niosh/docs/89-102/89-102. pdf [accessed 2 February 2017].

NTP (National Toxicology Program). 2008. Chemical information for bisphenol AF [CASRN 1478-61-1] https://ntp.niehs.nih.gov/ntp/htdocs/chem_background/ exsumpdf/bisphenolaf_093008_508.pdf [accessed 2 February 2017]

Okabayashi K, Watanabe T. 2010. Excretion of bisphenol A into rat milk. Toxicol Mech Methods 20(3):133-136, PMID: 20163291, https://doi.org/10.3109/15376511003646689.

Padilla-Banks E, Jefferson WN, Newbold RR. 2006. Neonatal exposure to the phytoestrogen genistein alters mammary gland growth and developmental programming of hormone receptor levels. Endocrinology 147(10):4871-4882, PMID: 16857750, https://doi.org/10.1210/en.2006-0389.

Palanza P, Gioiosa L, vom Saal FS, Parmigiani S. 2008. Effects of developmental exposure to bisphenol A on brain and behavior in mice. Environ Res 108(2):150157, PMID: 18949834.
Pelch KE, Wignall JA, Goldstone AE, Ross PK, Blain RB, Shapiro AJ, et al. 2017. NTP research report on biological activity of bisphenol A (BPA) structural analogues and functional alternatives. NTP RR4. https://ntp.niehs.nih.gov/ntp/results/pubs/rr/ reports/rr04_508.pdf [accessed 27 November 2017].

Perez P, Pulgar R, Olea-Serrano F, Villalobos M, Rivas A, Metzler M, et al. 1998. The estrogenicity of bisphenol A-related diphenylalkanes with various substituents at the central carbon and the hydroxy groups. Environ Health Perspect 106(3):167-174, PMID: 9449681.

Pinney SE, Mesaros CA, Snyder NW, Busch CM, Xiao R, Aijaz S, et al. 2017. Second trimester amniotic fluid bisphenol A concentration is associated with decreased birth weight in term infants. Reprod Toxicol 67:1-9, PMID: 27829162, https://doi.org/10.1016/j.reprotox.2016.11.007.

Rivas A, Lacroix M, Olea-Serrano F, Laíos I, Leclercq G, Olea N. 2002. Estrogenic effect of a series of bisphenol analogues on gene and protein expression in MCF-7 breast cancer cells. J Steroid Biochem Mol Biol 82(1):45-53, PMID: 12429138.

Rochester JR. 2013. Bisphenol A and human health: a review of the literature. Reprod Toxicol 42:132-155, PMID: 23994667, https://doi.org/10.1016/.reprotox 2013.08.008.

Rosenmai AK, Dybdahl M, Pedersen M, van Vugt-Lussenburg BMA, Wedebye EB, Taxvig C, et al. 2014. Are structural analogues to bisphenol A safe alternatives? Toxicol Sci 139(1):35-47, PMID: 24563381, https://doi.org/10.1093/toxsci/kfu030.

Rudel RA, Fenton SE, Ackerman JM, Euling SY, Makris SL. 2011. Environmental exposures and mammary gland development: state of the science, public health implications, and research recommendations. Environ Health Perspect 119(8):1053-1061, PMID: 21697028, https://doi.org/10.1289/ehp.1002864.

Rudmann D, Cardiff R, Chouinard L, Goodman D, Küttler K, Marxfeld H, et al. 2012. Proliferative and nonproliferative lesions of the rat and mouse mammary, Zymbal's, preputial, and clitoral glands. Toxicol Pathol 40(6 Suppl):7S-39S, PMID: 22949413, https://doi.org/10.1177/0192623312454242.

Russo J, Tait L, Russo IH. 1983. Susceptibility of the mammary gland to carcinogenesis. The cell of origin of rat mammary carcinoma. Am J Pathol 113(1):50-66, PMID: 6312803.

Ryan BC, Vandenbergh JG. 2006. Developmental exposure to environmental estrogens alters anxiety and spatial memory in female mice. Horm Behav 50(1):8593, PMID: 16540110, https://doi.org/10.1016/j.yhbeh.2006.01.007.

Sapouckey SA, Kassotis CD, Nagel SC, Vandenberg LN. 2018. Prenatal exposure to unconventional oil and gas operation chemical mixtures altered mammary gland development in adult female mice. Endocrinology 1:159(3):1277-1289, PMID: 29425295, https://doi.org/10.1210/en.2017-00866.

SAS/STAT(R) 9.2 User's Guide, Second Ed. Jonckheere-Terpstra Test. https:// support.sas.com/documentation/cdl/en/statug/63033/HTML/default/viewer.htm\# statug_freq_a0000000646.htm. [accessed 27 March 2018].

SAS/STAT(R) 9.2 User's Guide, Second Ed. Cochran-Armitage Test for Trend https:// support.sas.com/documentation/cdl/en/statug/63033/HTML/default/viewer.htm\# statug_freq_a0000000645.htm. [accessed 27 March 2018].

Schönfelder G, Wittfoht W, Hopp H, Talsness CE, Paul M, Chahoud I. 2002. Parent bisphenol $A$ accumulation in the human maternal-fetal-placental unit. Environ Health Perspect 110(11):A703-A707, PMID: 12417499.

Son WC, Gopinath C. 2004. Early occurrence of spontaneous tumors in CD-1 mice and Sprague-Dawley rats. Toxicol Pathol 32(4):371-374, PMID: 15307208, https:/doi.org/ 10.1080/01926230490440871.

Song SJ, Ruan T, Wang T, Liu RZ, Jiang GB. 2012. Distribution and preliminary exposure assessment of bisphenol AF (BPAF) in various environmental matrices around a manufacturing plant in China. Environ Sci Technol 46(24):1313613143, PMID: 23151244, https://doi.org/10.1021/es303960k.

Speroni L, Voutilainen M, Mikkola ML, Klager SA, Schaeberle CM, Sonnenschein $C$, et al. 2017. New insights into fetal mammary gland morphogenesis: differential effects of natural and environmental estrogens. Sci Rep 7:40806, PMID: 28102330, https://doi.org/10.1038/srep40806.

Sprague BL, Trentham-Dietz A, Hedman CJ, Wang J, Hemming JD, Hampton JM, et al. 2013. Circulating serum xenoestrogens and mammographic breast density. Breast Cancer Res 15(3):R45, PMID: 23710608, https://doi.org/10.1186/bcr3432.

Stanko JP, Easterling MR, Fenton SE. 2015. Application of Sholl analysis to quantify changes in growth and development in rat mammary gland whole mounts. Reprod Toxicol 54:129-135, PMID: 25463529, https://doi.org/10.1016/j.reprotox.2014. 11.004.

Stanko JP, Fenton SE. 2017. Quantifying branching density in rat mammary gland whole-mounts using the Sholl analysis method. J Vis Exp (125): e55789, PMID: 28745626, https://doi.org/10.3791/55789.

Sun Y, Irie M, Kishikawa N, Wada M, Kuroda N, Nakashima K. 2004. Determination of bisphenol $A$ in human breast milk by HPLC with column-switching and fluorescence detection. Biomed Chromatogr 18(8):501-507, PMID: 15386523, https://doi.org/10.1002/bmc.345.

Thayer KA, Taylor KW, Garantziotis S, Schurman SH, Kissling GE, Hunt D, et al. 2016. Bisphenol A, bisphenol S, and 4-hydroxyphenyl 4-isoprooxyphenylsulfone 
(BPSIP) in urine and blood of cashiers. Environ Health Perspect 124(4):437-444, PMID: 26309242, https://doi.org/10.1289/ehp.1409427.

Thigpen JE, Setchell KD, Kissling GE, Locklear J, Caviness GF, Whiteside T, et al. 2013. The estrogenic content of rodent diets, bedding, cages, and water bottles and its effect on bisphenol A studies. J Am Assoc Lab Anim Sci 52(2):130-141, PMID: 23562095.

Timms BG, Howdeshell KL, Barton L, Bradley S, Richter CA, vom Saal FS. 2005. Estrogenic chemicals in plastic and oral contraceptives disrupt development of the fetal mouse prostate and urethra. Proc Natl Acad Sci USA 102(19):70147019, PMID: 15867144, https://doi.org/10.1073/pnas.0502544102.

Todaka E, Mori C. 2002. Necessity to establish new risk assessment and risk communication for human fetal exposure to multiple endocrine disruptors in Japan. Congenit Anom (Kyoto) 42(2):87-93, PMID: 12196705.

Trabert B, Falk RT, Figueroa JD, Graubard BI, Garcia-Closas M, Lissowska J, et al. 2014. Urinary bisphenol A-glucuronide and postmenopausal breast cancer in Poland. Cancer Causes Control 25(12):1587-1593, PMID: 25189422, https://doi.org/ 10.1007/s10552-014-0461-8.

Troisi R, Hatch EE, Titus-Ernstoff L, Hyer M, Palmer JR, Robboy SJ, et al. 2007. Cancer risk in women prenatally exposed to diethylstilbestrol. Int $\mathrm{J}$ Cancer 121(2):356-360, PMID: 17390375, https://doi.org/10.1002/ijc.22631.

Tucker DK, Macon MB, Strynar MJ, Dagnino S, Andersen E, Fenton SE. 2015. The mammary gland is a sensitive pubertal target in CD-1 and C57BL/6 mice following perinatal perfluorooctanoic acid (PFOA) exposure. Reprod Toxicol 54:2636, PMID: 25499722, https://doi.org/10.1016/j.reprotox.2014.12.002.

Tucker DK, Foley JF, Hayes-Bouknight SA, Fenton SE. 2016. Preparation of highquality hematoxylin and eosin-stained sections from rodent mammary gland whole mounts for histopathologic review. Toxicol Pathol 44(7):1059-1064, PMID: 27474221, https://doi.org/10.1177/0192623316660769.

Tucker DK, Foley JF, Bouknight SA, Fenton SE. 2017. Sectioning mammary gland whole mounts for lesion identification. J Vis Exp, PMID: 28784953, https://doi.org/ $10.3791 / 55796$.

U.S. EPA. (U.S. Environmental Protection Agency). 2010. Bisphenol A action plan. https://www.Epa.Gov/sites/production/files/2015-09/documents/bpa_action_ plan.Pdf. [accessed 23 March 2018].

U.S. EPA. 1988. IRIS Assessment. Bisphenol A; CASRN 80-05-7. https://cfpub.epa. gov/ncea/iris/iris_documents/documents/subst/0356_summary.pdf [accessed 2 October 2017].

U.S. FDA (U.S. Food and Drug Administration). 2014. Bisphenol A (BPA): Use in food contact application. http://www.fda.gov/newsevents/publichealthfocus/ ucm064437.htm\#regulations [accessed 50 ctober 2016].

Vandenberg LN, Maffini MV, Schaeberle CM, Ucci AA, Sonnenschein C, Rubin BS, et al. 2008. Perinatal exposure to the xenoestrogen bisphenol-A induces mammary intraductal hyperplasias in adult CD-1 mice. Reprod Toxicol 26(3-4):210219, PMID: 18938238, https://doi.org/10.1016/j.reprotox.2008.09.015.
Vandenberg LN, Hunt PA, Myers JP, vom Saal FS. 2013. Human exposures to bisphenol A: mismatches between data and assumptions. Rev Environ Health 28(1):37-58, PMID: 23612528, https://doi.org/10.1515/reveh-2012-0034.

Wadia PR, Vandenberg LN, Schaeberle CM, Rubin BS, Sonnenschein C, Soto AM. 2007. Perinatal bisphenol A exposure increases estrogen sensitivity of the mammary gland in diverse mouse strains. Environ Health Perspect 115(4):592598, PMID: 17450229, https://doi.org/10.1289/ehp.9640.

Wang L, Zhang Z, Xu X, Zhang D, Wang F, Zhang L. 2015. Simultaneous determination of four trace level endocrine disrupting compounds in environmental samples by solid-phase microextraction coupled with HPLC. Talanta 142:97-103, PMID: 26003697, https://doi.org/10.1016/.t.talanta.2015.04.043.

Weber Lozada K, Keri RA. 2011. Bisphenol A increases mammary cancer risk in two distinct mouse models of breast cancer. Biol Reprod 85(3):490-497, PMID: 21636739, https://doi.org/10.1095/biolreprod.110.090431.

Weinhouse C, Anderson OS, Bergin IL, Vandenbergh DJ, Gyekis JP, Dingman MA, et al. 2014. Dose-dependent incidence of hepatic tumors in adult mice following perinatal exposure to bisphenol A. Environ Health Perspect 122(5):485-491, PMID: 24487385, https://doi.org/10.1289/ehp.1307449.

White SS, Stanko JP, Kato K, Calafat AM, Hines EP, Fenton SE. 2011. Gestational and chronic low-dose PFOA exposures and mammary gland growth and differentiation in three generations of CD-1 mice. Environ Health Perspect 119(8):1070-1076, PMID: 21501981, https://doi.org/10.1289/ehp.1002741.

WHO (World Health Organization). 2009. Bisphenol A (BPA)- current state of knowledge and future actions by WHO and FAO. http://www.Who.Int/foodsafety/publications/ fs_management/no_05_bisphenol_a_nov09_en.Pdf [accessed 2 October 2017].

WHO. 2010. Joint FAOMHO expert meeting to review toxicological and health aspects of bisphenol A: Summary report including report of stakeholders meeting on bisphenol A. http://apps.who.int/iris/bitstream/10665/44624/1/97892141564274_eng. pdf [accessed 20 ctober 2017].

Yang M, Ryu JH, Jeon R, Kang D, Yoo KY. 2009. Effects of bisphenol A on breast cancer and its risk factors. Arch Toxicol 83(3):281-285, PMID: 18843480, https://doi.org/10. 1007/s00204-008-0364-0.

Yang Y, Guan J, Yin J, Shao B, Li H. 2014. Urinary levels of bisphenol analogues in residents living near a manufacturing plant in south China. Chemosphere 112:481-486, PMID: 25048943, https://doi.org/10.1016/j.chemosphere.2014.05. 004

Ye X, Wong LY, Kramer J, Zhou X, Jia T, Calafat AM. 2015. Urinary concentrations of bisphenol $\mathrm{A}$ and three other bisphenols in convenience samples of U.S. adults during 2000-2014. Environ Sci Technol 49(19):11834-11839, PMID: 26360019, https://doi.org/10.1021/acs.est.5b02135.

Zhu Y, Aupperlee MD, Haslam SZ, Schwartz RC. 2017. Pubertally initiated high-fat diet promotes mammary tumorigenesis in obesity-prone FVB mice similarly to obesity-resistant BALB/c mice. Transl Oncol 10(6):928-935, PMID: 29024822, https://doi.org/10.1016/j.tranon.2017.09.004. 